\title{
Distinct Deep Short-Axon Cell Subtypes of the Main Olfactory Bulb Provide Novel Intrabulbar and Extrabulbar GABAergic Connections
}

\author{
Mark D. Eyre, Miklos Antal, and Zoltan Nusser \\ Laboratory of Cellular Neurophysiology, Institute of Experimental Medicine, 1083 Budapest, Hungary
}

\begin{abstract}
A universal feature of neuronal microcircuits is the presence of GABAergic interneurons that control the activity of glutamatergic principal cells and each other. In the rat main olfactory bulb (MOB), GABAergic granule and periglomerular cells innervate mitral and tufted cells, but the source of their own inhibition remains elusive. Here, we used a combined electrophysiological and morphological approach to investigate a rather mysterious cell population of the MOB. Deep short-axon cells (dSACs) of the inframitral layers are GABAergic and have extensive and characteristic axonal ramifications in various layers of the bulb, based on which unsupervised cluster analysis revealed three distinct subtypes. Each dSAC subtype exhibits different electrical properties but receives similar GABAergic and glutamatergic inputs. The local axon terminals of all dSAC subtypes selectively innervate GABAergic granule and periglomerular cells and


superficial layers. Another subpopulation (GCL-dSACs) is labeled by retrogradely transported fluorescent microspheres injected into higher olfactory areas, constituting a novel projection-cell population of the MOB. Our results reveal multiple dSAC subtypes, each specialized to influence MOB activity by selectively innervating GABAergic interneurons, and provide direct evidence for novel intrabulbar and extrabulbar GABAergic projections.
\end{abstract}

Key words: olfaction; inhibition; connectivity; immunohistochemistry; patch clamp; interneuron

\section{Introduction}

The extraordinary diversity of nerve cells was already recognized over a century ago (Ramón y Cajal, 1911). It is now widely accepted that within most brain regions, the glutamatergic principal cells are rather homogeneous, whereas the GABAergic nonprincipal cells, or interneurons (INs), form a much more diverse population (Freund and Buzsáki, 1996; Kosaka et al., 1998; Somogyi et al., 1998; McBain and Fisahn, 2001; Markram et al., 2004). Traditionally, the classification of IN types has relied primarily on their axonal and dendritic morphologies. However, recently their intrinsic electrical properties, gene expression profiles and firing behavior in relation to ongoing network activity have all been taken into account. Such combined molecular, morphological and physiological approaches have provided compelling evidence for the astonishing diversity of INs and for the variety of roles they play in neuronal networks. The classical view regarding the connectivity of INs has been that they primar-

\footnotetext{
Received June 3, 2008; accepted June 23, 2008.

This work was supported by a Wellcome Trust Project Grant, European Commission Integrated Project Grant LSHM-CT-2005-019055 (EUSynapse Project), and a European Young Investigator Award (www.esf.org/euryi) (Z.N.). We greatly acknowledge the financial support from these foundations. We thank Dr. László Kocsis for his help with the gap statistic, Dóra Rónaszéki for her excellent technical assistance, and Profs. Peter Somogyi, Jean-Marc Fritschy, and Werner Sieghart for kindly providing anti-GABA and $G A B A_{A} R \alpha 1$ subunit antibodies.

Correspondence should be addressed to Zoltan Nusser, Laboratory of Cellular Neurophysiology, Institute of Experimental Medicine, Hungarian Academy of Sciences, Szigony Street 43, 1083 Budapest, Hungary. E-mail: nusser@koki.hu.

DOI:10.1523/JNEUROSCI.2490-08.2008

Copyright $\odot 2008$ Society for Neuroscience $\quad 0270-6474 / 08 / 288217-13 \$ 15.00 / 0$
}

ily innervate the principal cells, and to a smaller extent each other. However, additional populations of hippocampal and neocortical INs have been revealed (Acsády et al., 1996; Gulyás et al., 1996, 2003; Meskenaite, 1997) that are specialized to selectively control the activity of other GABAergic INs, and the presence of such cells has also been suggested to occur in the main olfactory bulb (MOB) (Mugnaini et al., 1984; Gracia-Llanes et al., 2003).

In the MOB, information from olfactory sensory neurons is relayed to higher olfactory areas by glutamatergic principal cells, the mitral and tufted (M/T) cells (Shepherd et al., 2004). Primary olfactory axons synapse on the apical tufts of M/T cells in spherical neuropil regions called glomeruli. The principal cells are under the control of several GABAergic IN types. In the glomerular layer (GL), the highly diverse periglomerular cells (PGCs) exert their GABAergic influence on the apical tufts of M/T cells (Kosaka et al., 2001; Shepherd et al., 2004). In the external plexiform layer (EPL), axonless granule cells (GCs) establish reciprocal dendrodendritic synapses onto the lateral dendrites of M/T cells (Hirata, 1964; Jahr and Nicoll, 1980; Chen et al., 2000; Shepherd et al., 2004). As in many other brain regions, these GABAergic PGCs and GCs also receive GABAergic inputs (Price and Powell, 1970b; Pinching and Powell, 1971a; Puopolo and Belluzzi, 1998; Nusser et al., 1999; Smith and Jahr, 2002; Murphy et al., 2005; Pressler and Strowbridge, 2006), but their source is mostly unknown. A recent report (Pressler and Strowbridge, 2006) demonstrated that GCs receive $\mathrm{GABA}_{\mathrm{A}}$ receptor $\left(\mathrm{GABA}_{\mathrm{A}} \mathrm{R}\right)$-mediated inhibition from a subpopulation of inframitral short-axon cells 
(SACs), called Blanes cells, but it remains to be seen whether other cell types also contribute to the GABAergic control of GCs. Short-axon cells form another, rather diverse GABAergic IN population distinct from the numerically dominant GCs and PGCs (Ramón y Cajal, 1911; Price and Powell, 1970a; Schneider and Macrides, 1978; Mugnaini et al., 1984). Inframitral SACs are referred to as deep short-axon cells (dSACs) and have been subdivided into four groups based on their somatic and dendritic morphologies (Ramón y Cajal, 1911; Schneider and Macrides, 1978). However, very little is known about their axonal arborizations, their intrinsic electrical properties, their synaptic inputs, and their postsynaptic targets. Here, we aimed to provide a functional, molecular, and morphological characterization of dSACs to reveal their place in the olfactory bulb network. Our results demonstrate several new aspects of the diversity of dSACs, revealing three dSAC subtypes, each of which is specialized to regulate network activity through the selective control of other GABAergic INs. Furthermore, we provide direct evidence that a subpopulation of dSACs provide a novel GABAergic projection to higher olfactory areas.

\section{Materials and Methods}

In vivo injection of fluorescent microspheres. Male Wistar rats ( $n=11$ rats; $28-42 \mathrm{~d}$ old ) were anesthetized with $2 \mathrm{ml} / \mathrm{kg}$ of a 1:1 mixture of ketamine and xylazine and were mounted in a stereotaxic apparatus. Solutions of 40-nm-diameter fluorescent latex microspheres (as supplied by Invitrogen) were pressure injected $(100-300 \mathrm{nl})$ into the anterior olfactory nucleus, the olfactory tubercle, and the piriform cortex. After the surgery (3-14 d), acute horizontal slices from the MOB were prepared as described below.

Acute slice preparation and electrophysiological recordings. Acute horizontal slices from the MOB of male Wistar rats (20-49 d old) were prepared with a standard procedure, as described previously (Antal et al., 2006), in accordance with the ethical guidelines of the Institute of Experimental Medicine Protection of Research Subjects committee.

Somatic cell-attached and whole-cell recordings were performed at $31.5-34^{\circ} \mathrm{C}$ using an infrared differential interference contrast or an oblique illumination technique on an Olympus BX50WI microscope with a $40 \times$ water-immersion objective. Recordings were performed from visually identified cells with a somatic diameter of $>10 \mu \mathrm{m}$ located in the inframitral layers. For current-clamp experiments, a potassium gluconate-based intracellular solution was used [containing (in mM) 120 K-gluconate, $5 \mathrm{KCl}, 2 \mathrm{MgCl}_{2}$, 0.05 EGTA, 10 HEPES, $2 \mathrm{Mg}$-ATP, 0.4 Mg-GTP, 10 creatinine phosphate, and 8 biocytin, pH 7.33, osmolarity 270-290 mOsm]. After establishing the whole-cell configuration, if needed, hyperpolarizing or depolarizing DC current injections were applied to maintain cells at membrane potentials just below firing threshold. Trains of action potentials were then evoked by injecting 1-s-long depolarizing current pulses of $100 \mathrm{pA}$ in amplitude. The passive membrane properties were derived from single exponentials fitted to traces of membrane voltage responses to small amplitude (5-20 pA, $400 \mathrm{~ms}$ ) hyperpolarizing and depolarizing current injections. The same intracellular solution was used for recording the presynaptic dSACs during paired recordings in which 3-5 ms 2.5-4.0 nA currents were injected to evoke a single spike, which was repeated at either 25 or $50 \mathrm{~Hz}$ to evoke pairs of action potentials. To isolate AMPA receptor-mediated EPSCs, cells were voltage-clamped at $-70 \mathrm{mV}$ in the presence of $20 \mu \mathrm{M}$ 6-imino-3-(4methoxyphenyl)-1(6H)-pyridazinebutanoic acid hydrobromide (SR95531) and $50 \mu \mathrm{M}$ AP-5 in the bath solution. To examine spontaneous and action-potential-evoked inhibitory postsynaptic responses, a mixed potassium gluconate and potassium chloride internal solution was used [containing (in mM) $90 \mathrm{~K}$-gluconate, $40 \mathrm{KCl}, 2 \mathrm{MgCl}_{2}, 0.05$ EGTA, 10 HEPES, 2 Mg-ATP, $0.4 \mathrm{Mg}$-GTP, 10 creatinine phosphate, and 8 biocytin, pH 7.33, osmolarity $270-290$ mOsm]. For recording evoked IPSCs from PGCs, a mixed cesium methanesulfonate and cesium chloride internal solution was used [containing (in mM) $89 \mathrm{CsMeS}, 46 \mathrm{CsCl}$, $1 \mathrm{MgCl}_{2}, 0.16 \mathrm{CaCl}_{2}, 0.2$ EGTA, 15 HEPES, 4 Na-ATP, $0.4 \mathrm{Na}$-GTP, 15
TEA-Cl, 14 creatinine phosphate, pH 7.35, osmolarity 315 mOsm]. For sIPSCs, cells were voltage clamped at $-80 \mathrm{mV}$ and recordings were performed in the continuous presence of $20 \mu \mathrm{M}$ CNQX and either $50 \mu \mathrm{M}$ AP-5 or $5 \mu \mathrm{M}$ R-CPP [3-(( $R)$-2-carboxypiperazine-4-yl)-propyl-1phosphonic acid] in the bath solution (Tocris Bioscience). Miniature synaptic events were recorded in the presence of $1 \mu \mathrm{M}$ tetrodotoxin (TTX; Alomone Labs) to block voltage-gated sodium channels. For paired recordings, postsynaptic GCs were recorded with the same intracellular solution and were voltage-clamped at $-80 \mathrm{mV}$, but CNQX and AP5 were not included in the extracellular solution.

The following criteria were used to ensure the time independence of our data during the recordings. The access resistance $\left(R_{\mathrm{a}}\right)$ was subject to $75 \%$ compensation, and was continuously monitored. If $R_{\mathrm{a}}$ changed $>15 \%$ during the recording, the cell was discarded from the analysis. All recordings were rejected if the $R_{\mathrm{a}}$ became $>15 \mathrm{M} \Omega$.

Recordings were performed with a MultiClamp 700A amplifier (Molecular Devices). Patch pipettes of 3-5 M $\Omega$ were pulled (Zeitz Universal Puller) from thick-walled borosilicate glass capillaries with an inner filament ( $1.5 \mathrm{~mm}$ outer diameter, $0.86 \mathrm{~mm}$ inner diameter; Sutter Instrument). Data were digitized on-line at $20 \mathrm{kHz}$ and analyzed with EVAN 1.3 (Nusser et al., 2001a) and with an in-house analysis software (SPIN 1.0.1.) written in Matlab (Matlab 7.0; MathWorks). All chemicals, drugs, and reagents were purchased from Sigma unless stated otherwise.

Visualization of the recorded cells. After recordings, slices were placed in a fixative containing $4 \%$ paraformaldehyde, $1.25 \%$ glutaraldehyde and $15 \% \mathrm{v} / \mathrm{v}$ picric acid in $0.1 \mathrm{M}$ phosphate buffer $(\mathrm{PB} ; \mathrm{pH} 7.4)$ at $4^{\circ} \mathrm{C}$ for at least $24 \mathrm{~h}$. Before processing, the fixative was thoroughly washed out with $0.1 \mathrm{M}$ PB. Slices were then cryoprotected in 10 and $20 \%$ sucrose solutions (in $0.1 \mathrm{M} \mathrm{PB}$ ) for $45 \mathrm{~min}$ followed by freezing in liquid nitrogen and thawing in PB. After several washes in PB, slices were embedded in gelatin and resectioned at $60 \mu \mathrm{m}$ thickness. Biocytin was visualized using avidin-biotin-horseradish peroxidase complex overnight (ABC; Vector Laboratories) followed by a reaction with 3'3-diaminobenzidine tetrahydrochloride (DAB; $0.05 \%$ solution in Tris buffer, $\mathrm{pH} 7.4$ ) as chromogen and $0.01 \% \mathrm{H}_{2} \mathrm{O}_{2}$ as oxidant for $12 \mathrm{~min}$. Sections were then postfixed in $1 \% \mathrm{OsO}_{4}$ for $20 \mathrm{~min}$, stained in $1 \%$ uranyl acetate for $25 \mathrm{~min}$, dehydrated in a graded series of ethanol, and embedded in epoxy resin (Durcupan). This protocol extensively labeled the filled cell processes and masked epitopes for postembedding immunolabeling (see below), so in a number of slices an alternative method was used to visualize the biocytin. After freezing and resectioning, slices were incubated with $\mathrm{ABC}$ overnight followed by tyramide for $10 \mathrm{~min}$ (1:50 in solvent supplied; biotinylated TSA kit; PerkinElmer). Slices were then blocked in Tris-buffered saline (TBS) with $3 \%$ bovine serum albumin (BSA), $0.1 \%$ cold water fish skin gelatin (CWFSG; Aurion), and $0.05 \%$ azide for $60 \mathrm{~min}$ and then incubated with streptavidin-conjugated $1 \mathrm{~nm}$ gold particles (1:50; Aurion) in TBS with $0.8 \%$ BSA, $0.1 \%$ CWFSG and $0.05 \%$ azide overnight. Sections were then treated with $2 \%$ glutaraldehyde in TBS for $10 \mathrm{~min}$, followed by silver enhancement (Aurion SE-LM kit) for $30 \mathrm{~min}$ at $25^{\circ} \mathrm{C}$. Slices were then postfixed in $0.5 \% \mathrm{OsO}_{4}$ at $4^{\circ} \mathrm{C}$ for $15 \mathrm{~min}$, stained in $1 \%$ uranyl acetate for $25 \mathrm{~min}$, and dehydrated and embedded in Durcupan as above. For the retrogradely labeled cells, before the $\mathrm{ABC}-\mathrm{DAB}$ reaction, the biocytin was visualized with Alexa 488 or cyanine 5 (Cy5) conjugated to streptavidin, and the colocalization of biocytin and the fluorescent microspheres was confirmed using confocal laser-scanning microscopy.

Immunofluorescent microscopy. Slices were fixed after recordings as above except that the glutaraldehyde concentration of the fixative was only $0.05 \%$ and the fixative was thoroughly washed out after $3 \mathrm{~h}$. Slices were then cryoprotected, freeze-thawed and re-sectioned as above. Slices were blocked in TBS with 10\% normal goat serum (NGS; Vector Laboratories) for $1 \mathrm{~h}$ and then incubated overnight with anti-GABA $\mathrm{A}_{\mathrm{A}}$ receptor $\alpha 1$ subunit primary antibodies [diluted 1:500; gifts from Profs. J.-M. Fritschy (University of Zurich, Zurich, Switzerland) and W. Sieghart (Brain Research Centre, Vienna, Austria)] in TBST containing 2\% NGS (TBS with $2 \%$ NGS and $0.05 \%$ Triton X-100). Sections were then washed and incubated in a mixture of either streptavidin conjugated to Alexa 488 and goat anti-rabbit IgG conjugated to $\mathrm{Cy} 3$ or streptavidin conjugated to Cy5 and goat anti-rabbit IgG conjugated to Alexa 488 (all diluted 1:500 in 2\% NGS TBST; Alexa dyes were from Invitrogen; Cy dyes were from 
Jackson ImmunoResearch) for $2 \mathrm{~h}$. Slices were then washed in TBS, mounted, and viewed using an Olympus BX62 microscope equipped with appropriate fluorescence filters and a DP30BW CCD camera or an Olympus FV1000 confocal microscope. Biocytin was subsequently visualized with the ABC-DAB method and the slices were similarly dehydrated and embedded in Durcupan as above.

Three-dimensional reconstructions. Labeled cells were identified as dSACs from their size, the location of their somata, and their dendritic morphology. Neurons with no obvious truncations in their dendrites and axons were fully reconstructed with the Neurolucida system (MicroBrightField) attached to a Zeiss Axioscope 2 microscope using a $100 \times$ oil-immersion objective, and were subjected to morphometric measurements.

Electron microscopy and postembedding immunolabeling. Portions of recorded cells were re-embedded and serial sections were cut at $60 \mathrm{~nm}$ thickness using an ultramicrotome (Ultracut; Leica Microsystems). Sections were collected alternately onto copper and nickel pioloform-coated slot grids. Sections on nickel slot grids were subjected to postembedding immunoreactions for GABA, modified from those used by Somogyi and Hodgson (1985). Briefly, slot grids were treated with $1 \%$ periodic acid for $8 \mathrm{~min}$, followed by blocking with $50 \mathrm{~mm}$ glycine in $0.081 \% \mathrm{NaCl} \mathrm{TB}$ (TBLS) for $10 \mathrm{~min}$ and $1.5 \%$ BSA in TBLS for $30 \mathrm{~min}$. This was followed by incubation in primary rabbit-anti-GABA antibodies (GABA9; diluted in 1:500; gift from Prof. P. Somogyi, Medical Research Council, Oxford, UK) in TBLS containing 1.5\% BSA for $90 \mathrm{~min}$. The reaction was visualized with $10 \mathrm{~nm}$ gold-conjugated goat anti-rabbit secondary antibodies (British Biocell International; diluted 1:50 in TB with 1\% BSA and 0.5\% Tween 20). Sections were contrasted with uranyl acetate and lead citrate and viewed using a JEOL1011 electron microscope. Digital images were captured with a cooled CCD camera (Cantega; Soft Imaging System). Ultrastructurally identified $\mathrm{M} / \mathrm{T}$ cell apical and lateral dendrites were consistently immunonegative, verifying the specificity of our anti-GABA immunoreactions.

Statistical procedures. All data are expressed as mean \pm SD throughout this manuscript. The data were subject to the Shapiro-Wilk normality test, and the Levene and Brown-Forsythe or Hartley $F_{\max }$ tests for homogeneity of variances. The $t$ test for dependent samples or the Wilcoxon matched-pairs test were used to compare averaged spontaneous and miniature synaptic events within subtypes. At the individual-cell level, comparisons were performed using a nonparametric KolmogorovSmirnov test. Either parametric ANOVA or nonparametric KruskalWallis ANOVA was used to compare data between dSAC subtypes, depending on whether the distribution was normal or not. Where appropriate, data were further assessed by conducting a post hoc test (Tukey's unequal $n$ honestly significant difference test or multiple comparisons of mean ranks, respectively). All differences were considered significant if $p<0.05$. Morphological data were subjected to principal components analysis (PCA). The first four factors had eigenvalues $>1$ and were then used for agglomerative clustering of Euclidean distances using Ward's method. The gap statistic method (Tibshirani et al., 2001) was used to determine the number of clusters. All analyses (including analysis of parameter correlations, PCA, and unsupervised clustering) were performed using the Statistica software (version 6; StatSoft). The gap statistic calculation was implemented as a macro within the Statistica software.

\section{Results \\ Morphological diversity of deep short-axon cells}

Patch pipette recordings were performed from the somata of 158 neurons located below the mitral cell layer (MCL) in acute MOB slices obtained from postnatal day 20 (P20)-P41 rats. Cells with a somatic diameter of $>10 \mu \mathrm{m}$ were randomly selected in the internal plexiform (IPL) and granule cell (GCL) layers and were recorded first in cell-attached, and then in whole-cell configurations. After electrophysiological recordings, the slices were fixed and the biocytin-filled cells were subjected to neurochemical and morphological characterizations.

All of the recorded cells exhibited dendritic and axonal mor- phologies distinct from both M/T and GCs. The location and shape of the somata and the dendritic arbors of these cells were heterogeneous, and examples of all categories of dSACs described previously were observed. Large spiny Blanes cells (73 of 158) were the most frequent cell morphology encountered, whereas sparsely spiny large Golgi cells (28 of 158), medium-sized horizontal cells ( 42 of 158), and smaller Cajal cells (15 of 158) were less common. Because of the advantages offered by intracellular labeling techniques compared with Golgi impregnations, we were able to recover extensive axonal trees of the recorded cells. Many dSACs had a very extensive axonal arbor, ramifying in distinct layers of the MOB (Fig. 1). A substantial number of cells projected their axons across the EPL and ramified broadly in the GL. The majority of these branches encircled many glomeruli, and only a few collaterals were found in the EPL and GCL (Fig. $1 A, B)$. Their somata were elongated parallel to the MCL, and were often located in the IPL ( 32 of 51 cells). Their dendrites were either sparsely ( 30 of 51 cells) or densely ( 8 of 51 cells) spiny and predominantly confined to the IPL, corresponding to horizontal cells. The remaining cells ( 13 of 51 ) had an overall appearance of Golgi cells. In contrast, many other dSACs had axonal ramifications predominantly within the EPL, with some collaterals in the IPL and superficial GCL (Fig. $1 E, F$ ). The axonal arbor was dense, column-like, and had a characteristic sharp border between the EPL and GL; axons never entered the GL. The majority (72 of 79) displayed vertically polarized somata in the GCL and their stellate or vertically oriented dendrites were usually covered with spines (62 of 79 cells), giving them the appearance of Blanes cells (Fig. $1 F)$. However, some cells with similar axonal morphologies possessed smooth dendrites almost devoid of spines, typical of vertical Cajal cells (Fig. 1E) (14 of 79 cells). Finally, the smallest subset of dSACs had axonal arbors restricted to the GCL (Fig. $1 C, D)$. To exclude the possibility that the lack of axons in the superficial layers was the consequence of truncation during slice preparation, we discarded all such cells from our analysis. The somata of these cells were often located in the GCL ( 13 of 28 cells) and their dendrites were usually sparsely spiny ( 25 of 28 cells), having an overall appearance of horizontal or Golgi cells.

Thus, our analysis of the somatodendritic morphologies was in agreement with the classical Golgi studies, but when the axonal arborizations were also considered, a more complex picture emerged. To assess whether dSACs can be objectively divided into well-defined subpopulations based on both their axonal and dendritic morphologies, we reconstructed a subpopulation of these cells in three dimensions and subjected them to morphometric measurements. After principal components analysis, agglomerative clustering (see Materials and Methods) suggested three main subpopulations (Fig. $1 G$ ), which was confirmed using the gap statistic method (Tibshirani et al., 2001). Based on the predominant axonal arborizations of the subpopulations in different layers, they were termed as GL-, EPL-, and GCL-dSACs (Fig. 1). Our results also demonstrate that many morphological parameters (e.g., dendritic fractal index, axonal segment length, furthest axonal Sholl intercept) (Table 1) significantly differed among the subtypes.

\section{GCL-dSACs project to higher olfactory areas}

When the local axon collaterals of distinct dSAC subtypes were analyzed, we noticed that a branch of the main axon of GCLdSACs often entered the white matter and projected caudally in the lateral olfactory tract, suggesting that GCL-dSACs might form an extrabulbar projection (Kosaka and Kosaka, 2007). To address this issue directly, we injected fluorescent microspheres 
into many higher order olfactory areas, including the anterior olfactory nucleus (AON), the olfactory tubercle (Fig. 2), the piriform cortex (PCtx), and the deep endopiriform nucleus. Three to $14 \mathrm{~d}$ after surgery, in vitro slices were cut from the MOB and fluorescently labeled cells with inframitral somatic locations were recorded. After the characterization of their active and passive electrical properties and their synaptic inputs (see below), the presence of microspheres in the biocytin-filled cells was verified (Fig. $2 B_{1}-B_{3}$ ), followed by full morphological reconstructions. Figure $2 \mathrm{~A}$ shows the reconstruction of a $\mathrm{dSAC}$ with projection to the olfactory tubercle (Fig. 2C). The soma was located in the GCL, had horizontally oriented dendrites, and the local axon collaterals were also restricted to the inframitral layers. Qualitatively very similar axonal and dendritic arborizations were found in all 17 cells in which sufficient axons and dendrites were recovered after in vitro electrophysiological characterization $(n=42$ cells). The axodendritic morphologies of these retrogradely labeled cells (Fig. 2A) were indistinguishable from the randomly recorded and filled GCL-dSACs, but it remains to be seen whether all GCL-dSACs project outside the MOB.

\section{Molecular differences between dSACs}

We then addressed whether molecular differences also exist among dSAC subtypes. Previous immunolabeling studies have indicated that neuropeptide Y (NPY), vasoactive intestinal polypeptide (VIP), calbindin $(\mathrm{CB})$, and nitric oxide synthase (NOS) are neurochemical markers for dSACs in the inframitral layers. However, because these markers labeled very few cells (e.g., VIP and CB $<4 \%$ of all dSACs) (Eyre and Nusser, unpublished observation), we found none of them to be a good candidate as a selective marker of a particular dSAC subtype. In contrast, the $\mathrm{GABA}_{\mathrm{A}} \mathrm{R} \alpha 1$ subunit selectively labels the somatodendritic domain of a large population of nongranule cells in the inframitral layers of the MOB (supplemental Fig. $1 \mathrm{~A}$, available at www. jneurosci.org as supplemental material), making it a potential subtype-selective marker. As illustrated in supplemental Figure $1 A$ (available at www.jneurosci.org as supplemental material), only dSACs are immunopositive for this subunit in the GCL; the strong labeling of the EPL originates from M/T cells. A subset of the in vitro recorded cells $(n=50)$ was processed for immunolabeling for the $\mathrm{GABA}_{\mathrm{A}} \mathrm{R} \alpha 1$ subunit in conjunction with fluorescent visualization of the biocytin. All EPL-dSACs $(n=30$ cells) were intensely labeled for the $\alpha 1$ subunit (supplemental Fig. $1 C$, available at www.jneurosci.org as supplemental material). Eleven of 15 GL-dSACs were found to be moderately labeled (supplemental Fig. $1 B$, available at www.jneurosci.org as supplemental material), whereas two were strongly labeled and two appeared to be immunonegative. Finally, the majority ( 4 of 5 cells) of GCLdSACs were apparently immunonegative (supplemental Fig. $1 D$, available at www.jneurosci.org as supplemental material); only a single cell showed very weak immunoreactivity. These results clearly demonstrate that molecular differences exist, but future experiments will be needed to identify other dSAC subtypeselective molecular markers.

\section{Deep short-axon cells show distinct intrinsic electrical properties}

Given the morphological and molecular heterogeneity of dSACs, we also aimed to reveal potential subtype-specific differences in the electrical properties of the cells. Cell-attached recording before the establishment of the whole-cell configuration demonstrated differences in the spontaneous spiking activity of dSACs in acute in vitro slices. Both GL- and GCL-dSACs were found to be spontaneously active, whereas 27 of 28 EPL-dSACs were silent 
Table 1. Morphological parameters of dSACs

\begin{tabular}{|c|c|c|c|c|}
\hline Morphological parameters & GL-dSAC mean $\pm S D$ & EPL-dSAC mean $\pm S D$ & $\mathrm{GCL}-\mathrm{dSAC}$ mean $\pm \mathrm{SD}$ & $\overline{\text { ANOVA }}$ \\
\hline Soma major diameter ( $\mu \mathrm{m})$ & $20.0 \pm 5.6$ & $15.7 \pm 3.7$ & $20.1 \pm 6.1$ & ns \\
\hline Soma minor diameter $(\mu \mathrm{m})$ & $14.0 \pm 2.5^{\#, \dagger}$ & $11.4 \pm 2.3^{\#}$ & $10.2 \pm 2.4^{\dagger}$ & $* *$ \\
\hline Total dendrite length $(\mu \mathrm{m})$ & $2930 \pm 728$ & $2203 \pm 1293$ & $2076 \pm 845$ & ns \\
\hline Total number of dendrite branch points & $34 \pm 9$ & $34 \pm 19$ & $27 \pm 18$ & ns \\
\hline Total number of dendritic spines & $312 \pm 280$ & $272 \pm 179$ & $396 \pm 331$ & ns \\
\hline Dendrite vertex ratio & $1.12 \pm 0.37$ & $1.25 \pm 0.29$ & $0.97 \pm 0.68$ & ns \\
\hline Furthest dendrite Sholl intercept ( $\mu \mathrm{m})$ & $307 \pm 83$ & $180 \pm 42$ & $330 \pm 151$ & ns \\
\hline Dendrite fractal index & $1.09 \pm 0.05^{\#}$ & $1.09 \pm 0.04$ & $1.05 \pm 0.03^{\#}$ & * \\
\hline Total axon length $(\mu \mathrm{m})$ & $15435 \pm 8762$ & $14733 \pm 8985$ & $7783 \pm 9631$ & ns \\
\hline Axon mean segment length $(\mu \mathrm{m})$ & $39.0 \pm 8.8^{\#}$ & $13.6 \pm 4.6^{\#,+}$ & $34.8 \pm 14.5^{\dagger}$ & $* *$ \\
\hline Furthest axon Sholl intercept ( $\mu \mathrm{m})$ & $976 \pm 486^{\#}$ & $458 \pm 73^{\#,+}$ & $995 \pm 325^{\dagger}$ & $\neq \neq$ \\
\hline Axon fractal index & $1.21 \pm 0.10$ & $1.32 \pm 0.10$ & $1.16 \pm 0.16$ & * \\
\hline Mean \% of dendrite in MCL & $4.7 \pm 2.3$ & $3.2 \pm 4.4$ & $13.1 \pm 22.7$ & ns \\
\hline Mean $\%$ of dendrite in IPL & $68.9 \pm 15.0^{\#, t}$ & $20.2 \pm 11.2^{\#}$ & $19.6 \pm 23.9^{\dagger}$ & $\neq \neq$ \\
\hline Mean $\%$ of dendrite in GCL & $26.4 \pm 16.4^{\#}$ & $76.6 \pm 13.1^{\#}$ & $57.4 \pm 38.2$ & $\neq \ddagger$ \\
\hline Mean $\%$ of dendrite in WM & 0 & 0 & $9.9 \pm 17.1$ & ns \\
\hline Mean \% of axon in GL & $52.9 \pm 29.9^{\#, \dagger}$ & $0^{\#}$ & $0^{\dagger}$ & 抹 \\
\hline Mean \% of axon in EPL & $13.2 \pm 8.8$ & $57.0 \pm 22.7^{\#}$ & $0^{\#}$ & $\neq \ddagger$ \\
\hline Mean $\%$ of axon in MCL & $7.3 \pm 6.2$ & $18.2 \pm 9.5^{\#}$ & $1.3 \pm 2.6^{\#}$ & $\neq$ \\
\hline Mean \% of axon in IPL & $11.8 \pm 10.9$ & $16.2 \pm 9.4$ & $3.6 \pm 4.1$ & ns \\
\hline Mean $\%$ of axon in GCL & $14.5 \pm 12.1$ & $7.8 \pm 5.8^{\#}$ & $92.7 \pm 5.6^{\#}$ & $\neq$ \\
\hline Mean $\%$ of axon in WM & $0.4 \pm 1.2$ & 0 & $2.4 \pm 4.9$ & ns \\
\hline
\end{tabular}

The vertex ratio is a measure of the branching pattern of the dendrites; the furthest Sholl intercept is the radius of the largest virtual sphere centered on the soma that is still intercepted by the dendrite or the axon; and the fractal index is a measure of the space-filling nature of the object. ns, Not significant; WM, white matter.

${ }^{*} p<0.05,{ }^{* *} p<0.01$ (significant differences for parametric ANOVA), and ${ }^{\ddagger} p<0.05,{ }^{*{ }^{*}} p<0.01$ (for Kruskal-Wallis nonparametric ANOVA tests); ${ }^{*{ }^{+}} p<0.05$ (significant differences between the indicated pairs after pos hoc tests).

\section{A}
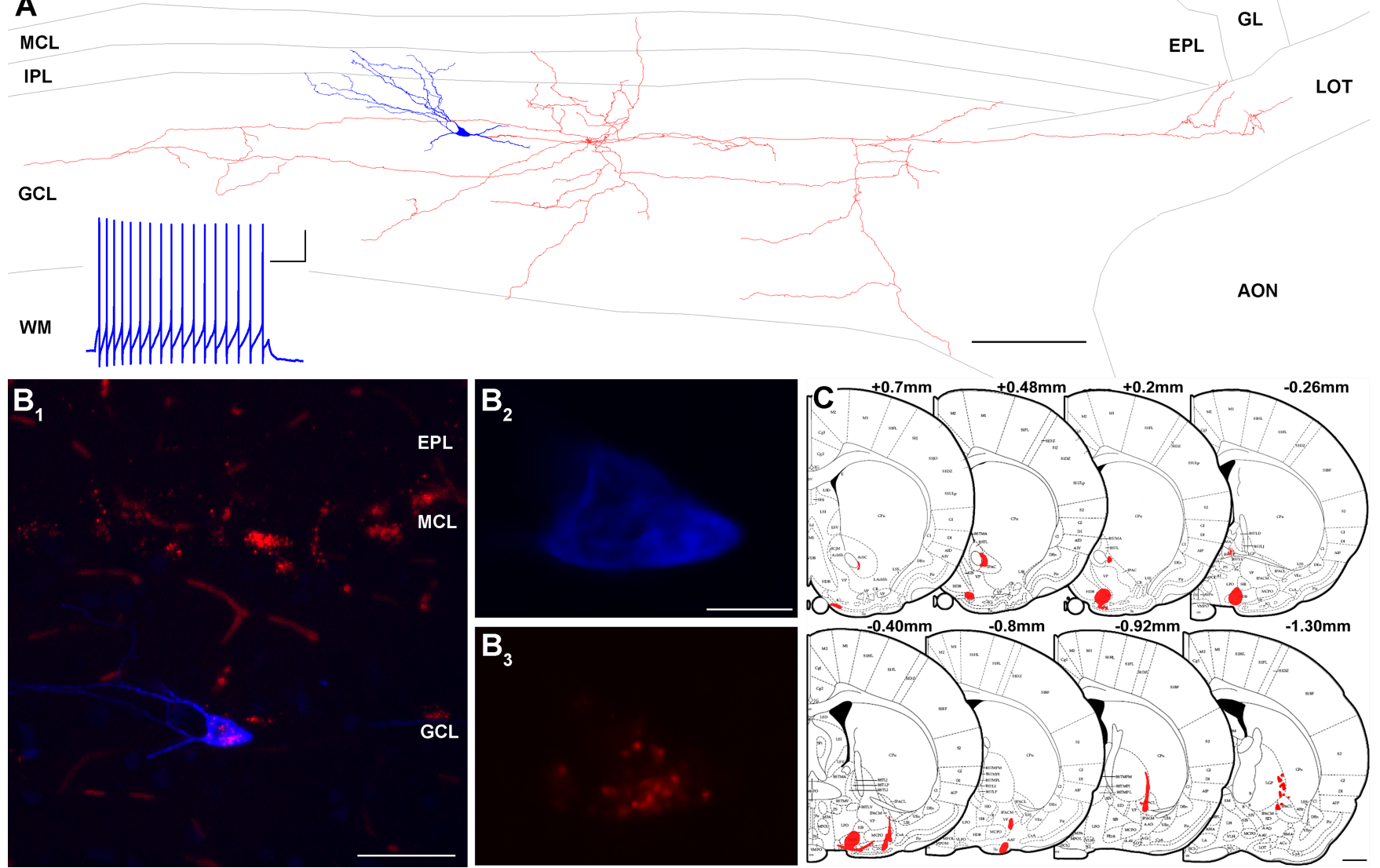

Figure 2. A GCL-dSAC with projection outside the MOB. A, Neurolucida reconstruction of a retrogradely labeled dSAC (MA1109) with dendrites (blue) and axons (red) confined to the inframitral layers. The axon extends throughout much of the $\mathrm{GCL}$ and enters the lateral olfactory tract. Inset, Voltage response of the cell to the injection of a 1-s-long $100 \mathrm{pA}$ depolarizing current. Calibration: $20 \mathrm{mV}, 200 \mathrm{~ms} . \boldsymbol{B}_{1}-\boldsymbol{B}_{3}$, Post hoc visualization of the intracellularly applied biocytin (blue) confirmed that the recorded cell contained fluorescent microspheres (red). Note that many mitral cells also contain the fluorescent microspheres. $C$, The injection site is shown superimposed on coronal maps (Paxinos and Watson, 1998) at eight rostrocaudal levels relative to bregma. The injection was mainly confined to the olfactory tubercle and horizontal diagonal band. Scale bars: $\boldsymbol{A}, 200 \mu \mathrm{m} ; \boldsymbol{B}_{1}, 50 \mu \mathrm{m}$; (in $\boldsymbol{B}_{2}$ ) $\boldsymbol{B}_{2}, \boldsymbol{B}_{3}, 10 \mu \mathrm{m} ; \boldsymbol{C}, 1 \mathrm{~mm}$. 
Table 2. Physiological parameters of dSACs

\begin{tabular}{|c|c|c|c|c|}
\hline Physiological parameters & GL-dSAC mean $\pm S D$ & EPL-dSAC mean $\pm S D$ & GCL-dSAC mean \pm SD & ANOVA \\
\hline Spontaneous firing activity $(\mathrm{Hz})$ & $7.41 \pm 6.54^{\#}$ & $0.25 \pm 1.31^{\#, \dagger}$ & $3.26 \pm 3.29^{\dagger}$ & $* *$ \\
\hline Input resistance (M $\Omega$ ) & $306.2 \pm 150.1^{\#}$ & $160.8 \pm 68.6^{\#, \dagger}$ & $406.6 \pm 180.7^{\dagger}$ & $* *$ \\
\hline Membrane time constant (ms) & $25.4 \pm 8.9^{\#}$ & $13.5 \pm 5.7^{\#, \dagger}$ & $32.8 \pm 18.6^{\dagger}$ & $* *$ \\
\hline Threshold of first AP (mV) & $-38.2 \pm 5.4$ & $-39.8 \pm 5.6^{\#}$ & $-35.1 \pm 3.2^{\#}$ & * \\
\hline Peak amplitude of first AP (mV) & $59.9 \pm 12.0$ & $62.1 \pm 15.3$ & $54.0 \pm 8.3$ & ns \\
\hline FWHM of first AP (ms) & $0.52 \pm 0.13$ & $0.53 \pm 0.11$ & $0.56 \pm 0.12$ & ns \\
\hline Amplitude of AHP of first AP (mV) & $14.0 \pm 5.1^{\#}$ & $11.2 \pm 3.5^{\#}$ & $13.1 \pm 2.2$ & * \\
\hline Decay time at $75 \%$ of AHP amplitude of first AP (ms) & $21.1 \pm 19.8^{\#}$ & $25.5 \pm 6.3^{\#, \dagger}$ & $12.4 \pm 7.5^{\dagger}$ & $* *$ \\
\hline Ratio of thresholds of last and first AP & $0.86 \pm 0.07^{\#, \dagger}$ & $0.73 \pm 0.47^{\#}$ & $0.74 \pm 0.14^{\dagger}$ & $* *$ \\
\hline Ratio of peak amplitude of last and first AP & $0.85 \pm 0.10$ & $0.82 \pm 0.07$ & $0.74 \pm 0.23$ & ns \\
\hline Ratio of FWHMs of last and first AP & $1.19 \pm 0.17^{\#}$ & $1.26 \pm 0.16^{\#}$ & $1.44 \pm 0.72$ & * \\
\hline Ratio of AHP amplitude of last and first AP & $1.17 \pm 0.37^{\#}$ & $1.32 \pm 0.23^{\#, \dagger}$ & $1.08 \pm 0.12^{\dagger}$ & $* *$ \\
\hline Ratio of last and first ISI & $1.84 \pm 0.92$ & $1.87 \pm 2.84$ & $1.64 \pm 0.61$ & ns \\
\hline Mean of ISI distribution (ms) & $36.4 \pm 19.1^{\#}$ & $40.1 \pm 8.8^{\dagger}$ & $21.1 \pm 7.8^{\#, \dagger}$ & $* *$ \\
\hline
\end{tabular}

AP, Action potential; AHP, spike afterhyperpolarization; FWHM, full-width at half-maximum amplitude; ISI, interspike interval; $n$ s, not significant.

${ }^{*} p<0.05,{ }^{* *} p<0.01$ (significant differences using Kruskal-Wallis nonparametric ANOVA); ${ }^{\sharp, t} p<0.05$ [significant difference using post hoc test (multiple comparisons of mean ranks) between the indicated pairs].

(Table 2). In whole-cell recordings, dSACs exhibited a variety of action potential firing patterns in response to 1-s-long $100 \mathrm{pA}$ depolarizing current injections (Fig. 1, insets). Quantitative analysis of a large number of parameters derived from the spike trains, individual spikes, and the passive electrical properties of the cells revealed significant dSAC subtype-specific differences and prominent within-subtype heterogeneity for many parameters (Table 2).

\section{Excitatory and inhibitory inputs onto deep short-axon cells}

To gain insights into the potential role of a neuron in a network, not only the morphological, molecular, and intrinsic electrical properties should be deciphered, but the synaptic connectivity must be determined as well. To investigate the synaptic inputs of dSACs, we performed in vitro voltage-clamp recordings of spontaneous EPSCs and IPSCs before and during the application of 1 $\mu \mathrm{M}$ TTX. Potential sources of glutamatergic excitation are either the local M/T cells or centrifugal inputs from the AON and PCtx (Shepherd et al., 2004). We argued that if TTX reduces the frequency of sEPSCs, then the cells providing the excitatory inputs must be present in the slice and should be spontaneously active. Figure $3 A$ shows representative recordings of AMPA receptormediated sEPSCs in the presence of $\mathrm{GABA}_{\mathrm{A}}$ and NMDA receptor antagonists for each dSAC subtype. Tetrodotoxin dramatically reduced the frequency and amplitude of sEPSCs in a GL- and an EPL-dSAC, and less dramatically in a GCL-dSAC (Fig. 3A,B). When examined at the population level, a significant decrease in EPSC frequency was detected in all subtypes without any change in the kinetics of the responses (Fig. 3C). The amplitude of sEPSCs was significantly reduced in GL- and EPL-, but not in GCLdSACs. We also noted the prevalence of bursts of sEPSCs in control conditions, which disappeared after TTX application, indicating that the sources of these synaptic currents are likely to be bursting external tufted (Hayar et al., 2004; Antal et al., 2006) or some mitral cells (Carlson et al., 2000). The amplitude, rise and decay kinetics showed no significant differences among the subtypes (Fig. $3 B, C$ ). The extremely rapid rise of the mEPSCs [10$90 \%$ rise time (RT), 230-300 $\mu$ s] suggests that neither asynchronous release nor dendritic filtering is severe in these cells. In addition, the identical decay time constants (weighted decay time constant $\tau_{\mathrm{w}}=1.4 \mathrm{~ms}$ for all subtypes) (Fig. 3C) indicate similar postsynaptic AMPA receptors and synaptic glutamate concentration waveforms. In summary, dSACs receive some of their AMPA receptor-mediated excitatory input from spontaneously active
$\mathrm{M} / \mathrm{T}$ cells. In agreement with this, electron microscopic (EM) analysis revealed that the presynaptic elements establishing asymmetrical synapses on dSACs were axon terminals (data not shown).

Next, the inhibitory inputs of dSAC subtypes were examined by recording sIPSCs using high- $\mathrm{Cl}^{-}$-containing intracellular solutions in the presence of the glutamate receptor antagonists CNQX and AP-5. The average frequency of sIPSCs ranged from $3.4-7.1 \mathrm{~Hz}$ under control conditions, which was significantly reduced after the application of TTX in all dSAC subtypes (Fig. 4). Application of TTX did not change the amplitudes of sIPSCs significantly, suggesting a low quantal content $(\sim 1)$ in all dSACs. Comparisons between dSAC subtypes showed no statistically significant differences in mIPSC amplitudes or kinetics (Fig. 4C). The fast rise times of mIPSCs $(10-90 \%$ rise time, $280-330 \mu \mathrm{s})$ also indicate the lack of both severe dendritic filtering and robust asynchronous release. The comparable mean decay time constants $\left(\tau_{\mathrm{w}}=2.3,2.6\right.$, and $2.9 \mathrm{~ms}$ for EPL-, GL-, and GCL-dSACs, respectively) suggest similar postsynaptic $\mathrm{GABA}_{\mathrm{A}}$ receptor subunit compositions and synaptic GABA concentration waveforms. These data demonstrate that all dSAC subtypes receive some of their fast synaptic inhibition from spontaneously active, local GABAergic interneurons. From our current knowledge of the MOB microcircuit, these could be either GCs or SACs. By using EM analysis, we found that the presynaptic elements of symmetrical synapses onto dSACs were exclusively GABA immunoreactive axon terminals. No evidence of dendrodendritic synapses, either established by or formed onto dSAC subtypes, was observed, suggesting that the majority of the GABAergic inputs of dSACs originate from SACs (data not shown).

\section{The postsynaptic targets of GABAergic dSACs are other GABAergic interneurons}

After the identification of the synaptic inputs of dSACs, we performed EM analysis of the postsynaptic targets of biocytin-filled $\mathrm{dSAC}$ axon terminals. In addition to the classification of postsynaptic profiles based on ultrastructural features, their neurotransmitter content was also revealed using postembedding immunogold labeling for GABA. Axon terminals of GL-dSACs $(n=3$ cells) ramifying in the juxtaglomerular space established symmetrical synapses onto small-diameter somata (5 synapses), and large- (22 synapses) and small-diameter (17 synapses) dendrites, which all showed ultrastructural features of PGCs (Fig. 5A,B) and were immunopositive for GABA (Figs. 5B, $6 A_{1}, A_{2}$ ). Because 
A
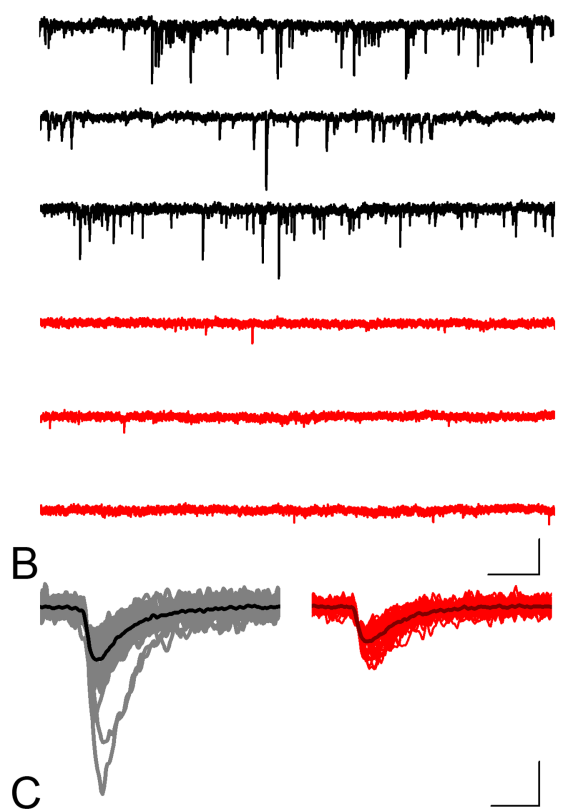

C

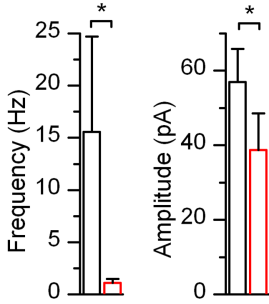

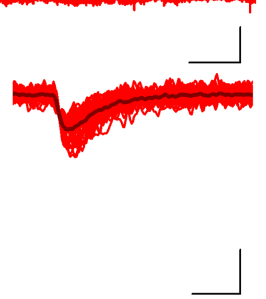



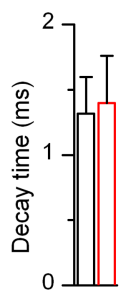
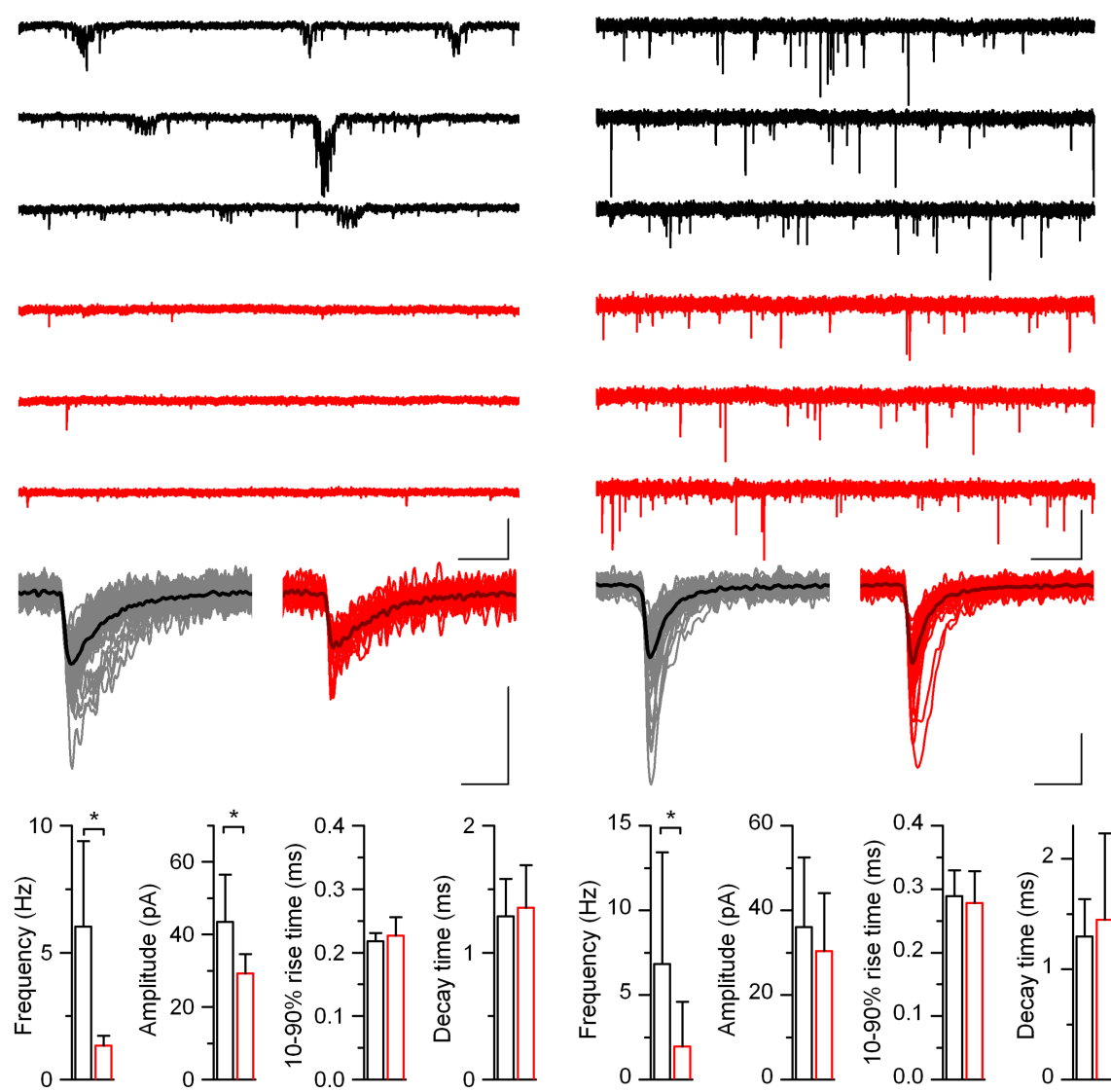

Figure 3. TTX reduces the amplitude and frequency of sEPSCs in a cell type-specific manner. $A$, Representative recordings of spontaneous EPSCs before (black traces) and after (red traces) bath application of $1 \mu \mathrm{M} \mathrm{TTX}$, in the presence of $20 \mu \mathrm{m}$ SR95531 and $50 \mu \mathrm{m} \mathrm{AP-5}$. Note the large reduction in the frequency and amplitude of EPSCs in GL (MA934) and EPL (MA889), and the moderate change in GCL-dSACs (MA915). Calibrations: 100 pA, $200 \mathrm{~ms}$. B, Consecutive individual spontaneous (gray traces) and miniature (red traces) EPSCs are shown superimposed on an extended time scale with their corresponding averaged traces (black and dark red, respectively). Calibrations: $50 \mathrm{pA}, 2 \mathrm{~ms}$. C, Summary plots of the effect of TTX on the frequency, amplitude, and kinetics of EPSCs in all dSAC subtypes. For GL- $\left(n=6\right.$ cells), EPL- $(n=6)$, and GCL- $(n=12)$ dSACS, TTX resulted in a significant (Wilcoxon matched-pair test, $\left.{ }^{*} p<0.05\right)$ reduction in the frequency without affecting the kinetics of the responses. The amplitude of sEPSCS was significantly reduced in GL- and EPL-, but not in GCL-dSACs. Error bars indicate SD.

PGCs form a very diverse cell population, we asked whether GL$\mathrm{dSAC}$ axons selectively innervate a single subpopulation or indiscriminately synapse on all cell types. Using fluorescent immunolabeling for tyrosine hydroxylase and CB, and visualizing biocytin in the intracellularly filled axons, we found that at least these two neurochemically defined PGC subpopulations are among the postsynaptic targets of GL-dSACs. In addition, axon collaterals of one GL-dSAC ramifying in the EPL ( $n=10$ synapses) and a different one with collaterals in the GCL ( $n=4$ synapses) were found to synapse exclusively on GC dendrites. Next, the postsynaptic targets of EPL-dSAC ( $n=4$ cells) axons were examined in the EPL, in which 38 of 43 synapses were formed onto GC dendritic shafts and the remaining five synapses established contacts onto GC gemmules (Fig. 5C,D). The ultrastructural identification of these targets was assisted by the presence of reciprocal dendrodendritic synapses with $\mathrm{M} / \mathrm{T}$ cells and their GABA immunoreactivity (Figs. $5 C, 6 B_{1}, B_{2}$ ). In the GCL, 38 axon terminals from three EPL-dSACs were also examined and 37 formed synapses onto GC dendrites. The only exception was a synapse onto the perisomatic region of a horizontally elongated soma in the IPL, which was strongly GABA immunopositive and was considered to be a dSAC. Finally, the axons of two GCL-dSACs were examined in the GCL. Of the 13 synapses analyzed, 11 contacted GC proximal dendrites and 2 contacted GC somata (Fig. 5E, F).
No evidence of synaptic contacts onto M/T cells was observed for any dSAC subtype in any layer.

Visualization of intracellular biocytin at the EM level with a $\mathrm{DAB}$ reaction results in an electron-dense precipitate throughout the cytoplasm (Fig. 5), preventing the access of primary antibodies to the aldehyde-fixed neurotransmitter molecules. To overcome this technical drawback, we visualized the intracellular biocytin with silver-enhanced ultrasmall gold particles (Fig. 6). This technique not only allowed three-dimensional light-microscopic reconstruction of the cells and unequivocal identification of the filled processes at the EM level, but the visualization of GABA in the filled profiles was also possible. For each dSAC subtype, all examined terminals were immunopositive for GABA, as were their postsynaptic target cells (Fig. 6).

Functional characterization of the synaptic outputs of dSACs Our ultrastructural data suggest that dSACs are GABAergic and that they provide synaptic inputs to local GABAergic interneurons. To functionally characterize the output of dSACs, we performed paired whole-cell recordings from presynaptic dSACs and postsynaptic GCs. In seven pairs, action potentials in the presynaptic dSACs induced short-latency, fast-rising, exponentially decaying inward currents in the postsynaptic GCs (Fig. 7, supplemental Fig. 2, available at www.jneurosci.org as supple- 

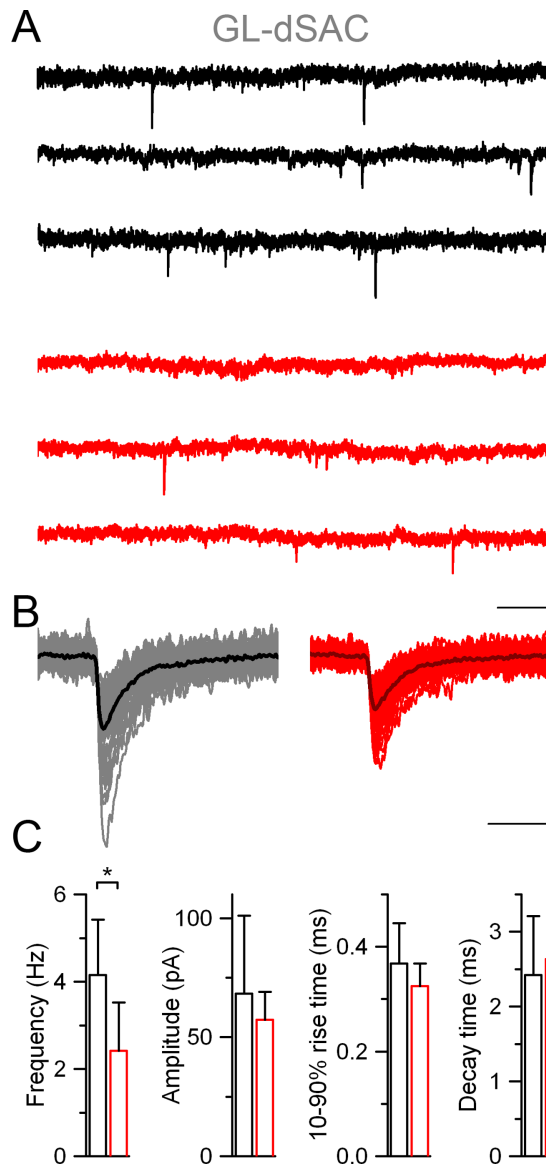

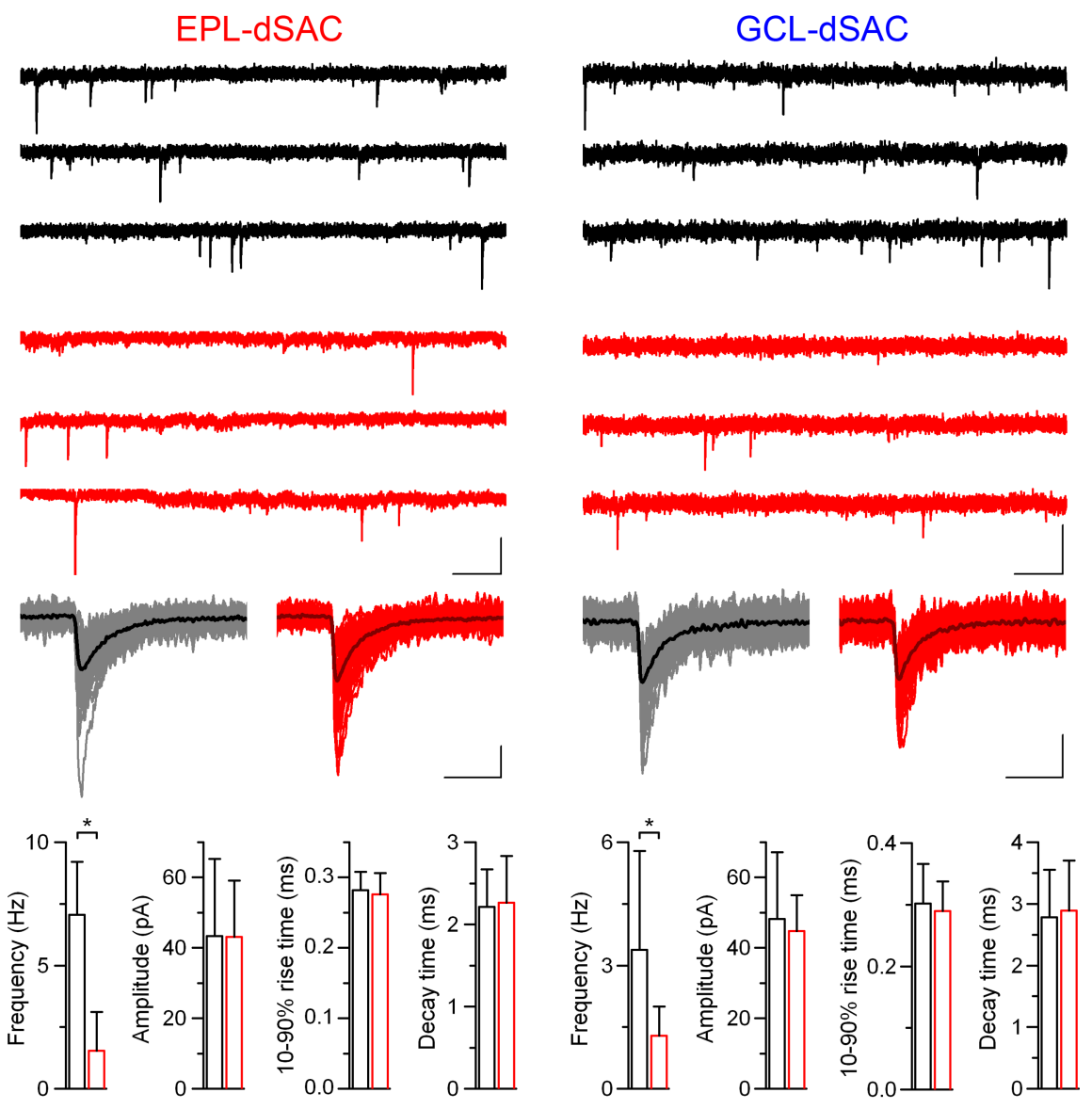

Figure 4. The effect of blocking the network activity with TTX on spontaneous IPSCS. A, Continuous current recordings before (black traces) and after (red traces) bath application of $1 \mu \mathrm{m}$ TTX, in the presence of $20 \mu \mathrm{m}$ CNQX and $50 \mu \mathrm{m} \mathrm{APV-5}$, are shown from individual cells of each dSAC subtype (GL: MA858; EPL: MA882; GCL: MA913). Calibrations: 40 pA, $200 \mathrm{~ms}$. B, Consecutive individual spontaneous (gray traces, average in black) and miniature (red traces, average in dark red) IPSCs are shown on an extended time scale. Calibrations: $20 \mathrm{pA}, 5 \mathrm{~ms}$. C, Summary of the effects of $1 \mu \mathrm{M}$ TTX on spontaneous IPSCs in GL- $\left(n=6\right.$ cells), EPL- $(n=5)$, and GCL- $(n=5)$ dSACS. For all three subtypes, a significant (Wilcoxon matched-pair test, $\left.{ }^{*} p<0.05\right)$ effect was detected only for IPSC frequency. Error bars indicate SD.

mental material). The short latency of the responses $[1.0 \pm 0.4$ ms; coefficient of variation $(\mathrm{CV})$ of the latencies, $0.18 \pm 0.8 ; n=$ 7] indicate the monosynaptic nature of the unitary IPSCs (uIPSCs). These results offer functional evidence for our EM predictions that GABAergic interneurons are the postsynaptic targets of dSACs. The specific GABA $_{\mathrm{A}} \mathrm{R}$ antagonist SR95531 completely and reversibly blocked uIPSCs in all of the six pairs tested (Fig. $7 B$ ), functionally validating our immunohistochemical results that dSACs are GABAergic. The amplitude of the uIPSCs showed large within-cell $(\mathrm{CV}, 1.5 \pm 0.8 ; n=7)$ and between-cell $(\mathrm{CV}$, 1.7) variability. Unitary IPSCs with small amplitudes had slow RTs, indicating severe dendritic filtering and distal dendritic locations of the synapses on the postsynaptic GC. When examining the kinetics of UIPSCs, we restricted our analysis to uIPSCs with $10-90 \%$ RT $<0.55 \mathrm{~ms}$. For the four pairs meeting this criterion, the $10-90 \%$ RT was $0.42 \pm 0.1 \mathrm{~ms}$ and the weighted decay time was $6.6 \pm 1.6 \mathrm{~ms}$, which is 2.5 -fold slower than that of mIPSCs recorded from dSACs $(2.6 \pm 0.6 \mathrm{~ms})$ (Fig. $4 C$ ). In two pairs, $1 \mu \mathrm{M}$ zolpidem, a benzodiazepine site agonist, prolonged the decay of uIPSCs. Next, we investigated the short-term plasticity of the postsynaptic responses. Two action potentials in the presynaptic dSACs were evoked at 50 or $25 \mathrm{~Hz}$, and their effects on uIPSC amplitudes were analyzed. The short-term plasticity showed large variability; some responses showed depression (Fig. 7B), some facilitation, and in one pair no plasticity was observed (supplemental Fig. $2 B$, available at www.jneurosci.org as supplemen- tal material). In this pair, however, changing the $\left[\mathrm{Ca}^{2+}\right]_{\mathrm{e}}$ revealed short-term facilitation and depression, and demonstrated that the plasticity depends on the initial release probability $\left(P_{\mathrm{r}}\right)$. Changing the $\left[\mathrm{Ca}^{2+}\right]_{\mathrm{e}}$ from 1 to $3 \mathrm{~mm}$ resulted in a ninefold increase in the success rate (from 0.05 to 0.45 ), but did not affect the mean postsynaptic response amplitude excluding failures (potency at low $P_{\mathrm{r}}=50.9 \pm 8.6 \mathrm{pA}$; high $P_{\mathrm{r}}=51.3 \pm 11.3 \mathrm{pA}$ ) (supplemental Fig. 2A, $C$, available at www.jneurosci.org as supplemental material), demonstrating the presence of a single functional release site. At this site, the $P_{\mathrm{r}}$ at $2 \mathrm{~mm}\left[\mathrm{Ca}^{2+}\right]_{\mathrm{e}}$ and $2 \mathrm{mM}$ $\left[\mathrm{Mg}^{2+}\right]_{\mathrm{e}}$ was 0.25 and the quantal size was $51 \mathrm{pA}$. The variance in the peak current of the successful events was remarkably small (CV, $\sim 0.2)$, indicating high postsynaptic receptor occupancy.

For post hoc identification of the recorded cells, biocytin was included in the intracellular solutions of both presynaptic and postsynaptic cells. In six of the seven pairs, the presynaptic cell was successfully recovered, yielding five EPL-dSACs and one GCL-dSAC (MA1066, physiology shown in supplemental Fig. 2, available at www.jneurosci.org as supplemental material). In four cases, the postsynaptic GC was also sufficiently filled for morphological identification. Unfortunately, the postsynaptic GC of the pair shown in supplemental Figure 2 (available at www. jneurosci.org as supplemental material) did not recover, precluding the anatomical determination of the number of synapses between the recorded cells. Figure 7A, however, shows a Neurolucida reconstruction of a presynaptic EPL-dSAC and its 

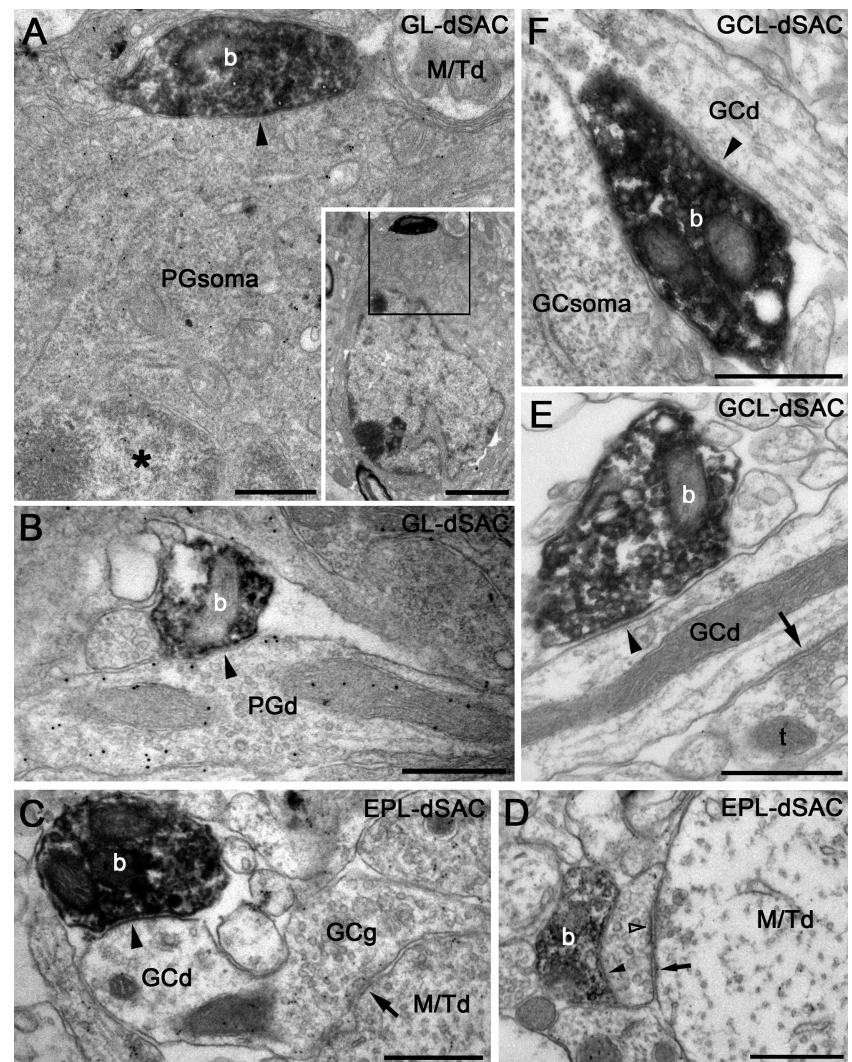

Figure 5. Deep short-axon cell subtypes selectively innervate other GABAergic interneurons. $A$, Electron micrograph showing an axon bouton ( $b$; black DAB precipitate) of a biocytin-filled GL-dSAC (MA324) forming a symmetrical synapse (arrowhead) onto the soma of a periglomerular neuron (PG soma). The section was immunoreacted for GABA (small gold particles) using the postembedding immunogold method. Inset, The area at a lower magnification. Note the absence of gold particles in the adjacent principal cell process (M/Td). $\boldsymbol{B}$, An axon bouton (b) of a GL-dSAC (MA324) in the GL forms a symmetrical synapse (arrowhead) onto a strongly GABAimmunopositive periglomerular cell dendrite (PGd). C, The postsynaptic target of an EPL-dSAC (MA340) in the EPL is a granule cell dendrite $(\mathrm{GCd})$. A gemmule $(\mathrm{GCg})$ emerges from this dendrite and forms a symmetrical synapse (arrow) onto a mitral/tufted dendrite (M/Td). Note the presence of immunogold particles labeling GABA in the vesicle-filled gemmule. $D, A$ bouton (b) of an EPL-dSAC (MA349) in the EPL establishes a symmetrical synapse (filled arrowhead) onto the gemmule of a granule cell, which forms a reciprocal synapse with a mitral/tufted profile (M/Td; open arrowhead, mitral- granule asymmetric synapse; arrow, granule-mitral symmetrical synapse). $\boldsymbol{E}, \boldsymbol{F}$, The postsynaptic targets of GCL-dSACs (MA372) in the $\mathrm{GCL}$ are granule cell dendrites (GCd). Note that in $\boldsymbol{E}$ the granule cell dendrite also receives a symmetrical synapse (arrow) from an unidentified axon terminal (t). Scale bars: $A-F, 500 \mathrm{~nm}$; inset in $A, 2 \mu \mathrm{m}$.

postsynaptic GC, and the positions and number of contact sites as determined at the LM level. The four putative synapses are consistent with the impression that this connection is mediated by multiple functional release sites, as implicated from the mean amplitude, its variability, failure rate, and the largest UIPSC recorded from this pair (Fig. 7B).

Despite our repeated efforts, we could not record GL-dSACPGC pairs, which is extremely challenging because of the enormous number of potential PGC targets within the area innervated by a single GL-dSAC. However, to provide a somewhat less direct functional evidence for the deep to superficial GABAergic connection in the MOB, we performed whole-cell recordings from PGCs and evoked IPSCs by extracellular stimulation in the IPL. In the presence of ionotropic glutamate receptor antagonists, extracellular stimulation in the IPL evoked short-latency $(1.9 \pm 0.5 \mathrm{~ms})$ inward currents of variable amplitudes (49.4 \pm 34.4 pA) (supplemental Fig. 3, available at www.jneurosci.org as
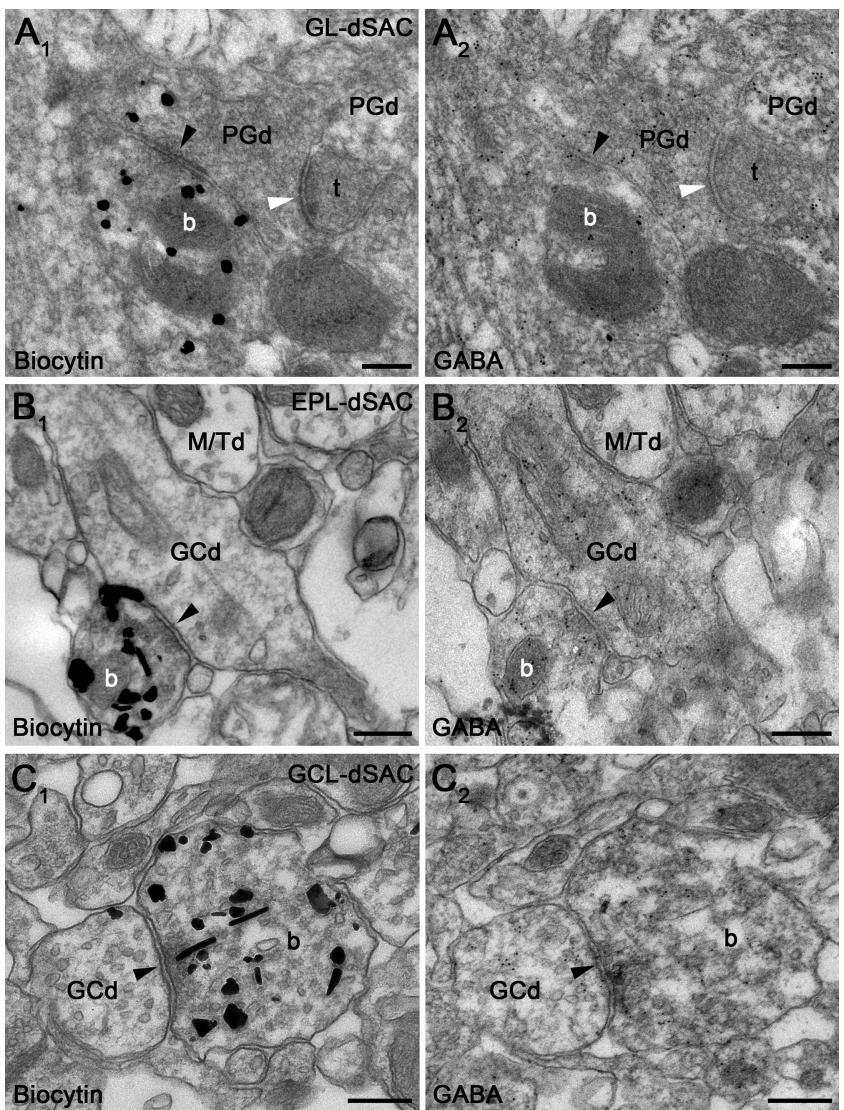

Figure 6. Deep short-axon cells are GABAergic. $A_{1}, A_{2}$, Serial ultrathin sections of a bouton (b) of a biocytin-filled (large silver-enhanced particles in $A_{1}$ ) GL-dSAC (MA633) in the GL. The GABA-immunopositive bouton (small gold particles in $A_{2}$ ) forms a symmetrical synapse (black arrowhead) onto a GABA-immunopositive periglomerular cell dendrite (PGd). The axon terminal ( $t$ ) that establishes an asymmetric synapse (white arrowhead) on the same dendrite is GABA immunonegative. $\boldsymbol{B}_{1}, \boldsymbol{B}_{2}$, Serial sections of a biocytin-filled (large silver particles in $\boldsymbol{B}_{1}$ ) EPLdSAC (MA796) in the EPL, which forms a symmetrical synapse (black arrowhead) onto a granule cell dendrite $(G C d)$. Both the presynaptic dSAC bouton and the postsynaptic dendrite contain a large number of gold particles labeling GABA. Note the lack of immunogold particles in the adjacent mitral/tufted cell dendrite (M/Td). $C_{1}, C_{2}$, Sequential ultrathin sections of a biocytinfilled (large silver particles in $\boldsymbol{C}_{7}$ ) GCL-dSAC (MA799) bouton in the GCL, forming a symmetrical synapse (black arrowhead) onto a granule cell dendrite (GCd). Both the biocytin-filled terminal and the postsynaptic dendrite contain small immunogold particles labeling GABA. The large silver particles are not visible in the sections $\boldsymbol{A}_{2}, \boldsymbol{B}_{2}$, and $\boldsymbol{C}_{2}$ because they were removed during the immunogold labeling procedure. Scale bars, $250 \mathrm{~nm}$.

supplemental material). The presence of glutamate receptor antagonists in the bath, the short and uniform latencies, and the monotonous rise indicate the monosynaptic nature of these IPSCs. The $\mathrm{GABA}_{\mathrm{A}}$ receptor blocker picrotoxin $(20 \mu \mathrm{M})$ completely and reversibly eliminated the inward currents, providing a functional demonstration of $\mathrm{GABA}_{\mathrm{A}}$ receptor-mediated deep to superficial layer connection in the MOB.

\section{Discussion}

In the present work, we provide evidence for the existence of three distinct dSAC subtypes in the MOB. Subtype-specific differences were found in their axo-somatodendritic morphologies, expression of the $\mathrm{GABA}_{\mathrm{A}} \mathrm{R} \alpha 1$ subunit, intrinsic electrical properties, and their postsynaptic target cells. GL-dSACs establish a novel intrabulbar GABAergic connection from deep to superficial layers, whereas GCL-dSACs directly signal the activity of the bulb to higher olfactory areas. Furthermore, we have also shown that all dSAC subtypes are GABAergic and they selectively inner- 


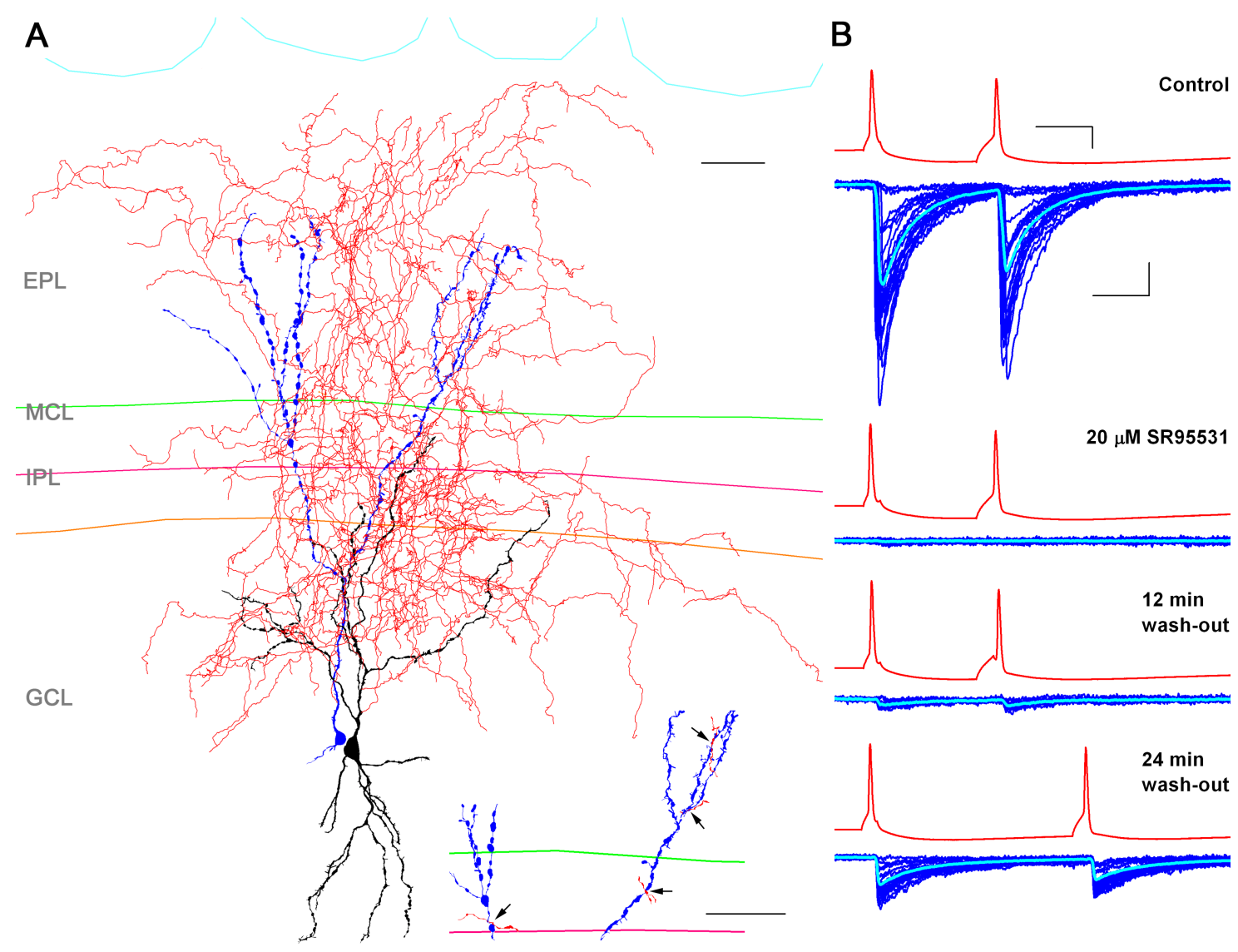

Figure 7. Unitary postsynaptic responses between an EPL-dSAC and a GC are mediated by $G_{A B A}$ receptors. $A$, Neurolucida reconstruction of a presynaptic EPL-dSAC (black, soma, dendrites; red, axon) and its postsynaptic GC (blue; MA1050). Inset, Positions of the potential contacts sites at a higher magnification. Scale bars, $50 \mu \mathrm{m}$. B, Pairs of action potentials $(50 \mathrm{~Hz})$ in the presynaptic dSAC (red traces) evoke fast rising ( $10-90 \% \mathrm{RT}, 0.33 \mathrm{~ms})$ and exponential decaying $\left(\tau_{\mathrm{w}}=6.1 \mathrm{~ms}\right)$ inward currents (blue, individual traces; light blue, averaged traces) in a granule cell (MA1050). The granule cell was held at $-80 \mathrm{mV}$ and was recorded with an intracellular solution containing high $\left[\mathrm{Cl}^{-}\right.$], yielding an $E_{\mathrm{Cl}}$ value of $\sim 30 \mathrm{mV}$. The unitary IPSCs displayed large amplitude variability (CV, 1.1). The averaged postsynaptic response showed slight paired-pulse depression. Bath application of the specific GABA $\mathrm{A}_{A}$ receptor antagonist SR95531 (20 $\left.\mu \mathrm{M}\right)$ abolished the inward currents. This effect could be partially recovered after the wash-out of the drug (bottom). Calibrations: voltage traces, $10 \mathrm{~ms}, 20 \mathrm{mV}$; current traces, $10 \mathrm{~ms}, 50 \mathrm{pA}$.

vate GABAergic PGCs and GCs. Using paired whole-cell recordings, we demonstrated that EPL- and GCL-dSACs innervate granule cells through the activation of $\alpha 2$ and $\gamma 2$ subunitcontaining $\mathrm{GABA}_{\mathrm{A}} \mathrm{Rs}$.

\section{Heterogeneity and classification of dSACs}

Early studies using the Golgi impregnation technique noted the morphological heterogeneity of olfactory bulb neurons, including dSACs (Blanes, 1898; Ramón y Cajal, 1911; Price and Powell, 1970a; Schneider and Macrides, 1978). Four categories of dSACs were distinguished based on characteristic morphological features such as (1) perpendicular (vertical Cajal cells) or (2) parallel (horizontal cells) dendrites relative to the bulbar lamination, or (3) a nonoriented dendritic arbor (Blanes and Golgi cells); and the (1) presence (Blanes cells) or (2) absence (Golgi, vertical Cajal, and horizontal cells) of dendritic spines. Other studies using immunolabeling techniques to visualize dSACs have described additional categories, including deep stellate cells in the monkey (Alonso et al., 1998; Crespo et al., 2001), pyriform and fusiform dSACs in the hedgehog (Briñón et al., 2001), and giant cells of the white matter in the rat (Briñón et al., 1992), but none have taken the axonal arborization of the cells into account.

We observed dSACs with somatodendritic morphologies reminiscent of all the classical categories. However, we could recover almost the entire axonal arbors of the recorded neurons, leading to the emergence of a much more complex picture. Cells with a similar somatodendritic morphology can possess very different axonal ramification patterns, and cells with a similar axonal arbor can have very different somatodendritic morphologies. For example, we observed both horizontal-like and Golgilike cells that predominantly innervated the GL, and conversely we identified cells with horizontally oriented dendrites that innervated either the GL or only the GCL. Because of this, we avoided the straightforward adaptation of the traditional classification and performed unsupervised cluster analysis of the cells based on both their axonal and dendritic arbors, which indicated the presence of 3 distinct dSAC subtypes. Additional dSAC subpopulations may exist, but our large sample size $(\sim 160 \mathrm{dSACs})$ indicates that they should comprise a very small fraction of all dSACs. Indeed, several neuropeptides (NPY, VIP, somatostatin), calcium binding proteins (CB, parvalbumin, calretinin, neurocalcin), some receptors ( $\mathrm{m} 2$ acetylcholine receptor), and enzymes (acetylcholinesterase, NADPH-diaphorase, NOS) have been used previously as dSAC markers, but were found to label only small subpopulations of dSACs (Nickell and Shipley, 1988; Briñón et al., 1992, 1999, 2001; Alonso et al., 1998, 2001; Crespo et al., 2000, 2002; Gracia-Llanes et al., 2003; Kosaka and Kosaka, 2007). Because of the lack of complete visualization of axonal and dendritic arbors after immunohistochemical labeling, it is impossible at present to determine whether these neurochemically identified dSACs form subsets of the GL-, EPL- or GCL-dSAC subtypes or whether they represent separate, nonoverlapping 
subpopulations. The latter is probably true for VIPimmunopositive dSACs that selectively innervate other VIPpositive dSACs (Gracia-Llanes et al., 2003). In our sample, we did not see any dSACs that selectively innervated other dSACs, but the lack of sampling of these VIP-positive cells is likely to be attributable to their rarity (Gracia-Llanes et al., 2003). Willhite et al. (2006) demonstrated that viral injection into the glomerular layer of the MOB resulted in column-like labeling of GCs and $\mathrm{M} / \mathrm{T}$ cells. The axonal arbor of EPL-dSACs could also be seen as another indication of the column-like organization of the MOB. It remains to be seen how the GC columns and the column-like axonal arbor of EPL-dSACs relate to each other in space.

\section{GCL-dSACs mediate a novel extrabulbar GABAergic projection}

Long-range GABAergic projections are a well-know feature of many brain regions where GABAergic cells form the sole output (e.g., cerebellar cortex, many nuclei of the basal ganglia) as well as areas where the primary projection is glutamatergic. For example, GABAergic projections from the neocortex (Gonchar et al., 1995) and hippocampus (Alonso and Köhler, 1982; Tóth and Freund, 1992; Jinno et al., 2007) have been described and their functional roles have been examined. In the MOB, glutamatergic $\mathrm{M} / \mathrm{T}$ cells provide the main output. They receive direct input from the axons of the olfactory sensory neurons and after complex local processing transfer the activity to higher olfactory areas. In the PCtx, M/T cell axons mainly target pyramidal cell apical dendrites and to a much smaller extent local circuit INs. Our results indicate that GCL-dSACs synthesize the activity of the MOB network by sampling excitation from a large number of $\mathrm{M} / \mathrm{T}$ cells probably associated with multiple glomeruli and therefore may participate in different representations (Xu et al., 2000). In turn, they then project this information to the same downstream olfactory areas as M/T cells. Revealing the postsynaptic target cells of GCL-dSAC axons in higher olfactory areas will be essential for understanding how they influence the activity of those brain regions. We hypothesize that the selective innervation of local circuit GABAergic interneurons in the PCtx would be an ideal method of synchronizing the rhythmic activity of the MOB with that of higher cortical areas (Laurent, 2002).

\section{Deep SACs are interneuron-selective interneurons}

When the potential functional roles of dSACs are considered, one of the most important issues is determining whether they use glutamate or GABA as the main neurotransmitter. The GABAergic nature of VIP-, NPY-, and CB-immunopositive dSAC subpopulations has been demonstrated previously (Gracia-Llanes et al., 2003). However, the fact that some juxtaglomerular SACs are suggested to be glutamatergic (Aungst et al., 2003) prompted us to perform postembedding immunogold reactions for GABA. Our EM analysis demonstrated that the axon terminals of all dSACs subtypes are GABA immunopositive and form symmetrical synapses onto their GABAergic postsynaptic target cells. In the last series of experiments, we performed paired whole-cell recordings between dSACs and GCs and found that the postsynaptic responses in six of six cells tested were completely and reversibly blocked by the $\mathrm{GABA}_{\mathrm{A}} \mathrm{R}$ antagonist SR95531. These experiments provided functional evidence for the GABAergic nature of EPL- and GCL-dSACs, and that at least some of their postsynaptic targets are GCs. EM examination of the postsynaptic target profiles of 152 synapses of nine dSACs revealed that $\mathrm{M} / \mathrm{T}$ cells are not among their postsynaptic targets, but they exclusively innervate other GABAergic INs. Such IN-selective INs are not unique to the MOB (Gracia-Llanes et al., 2003), as several subpopulations of interneuron-selective interneurons have also been described in the hippocampus (Acsády et al., 1996; Gulyás et al., 1996, 2003) and neocortex (Meskenaite, 1997).

\section{Novel intrabulbar connections between deep and superficial layers of the MOB}

The existence of dSACs with widespread axonal ramification almost exclusively in the GL is one of the most surprising findings of our study. To our knowledge, this is the first description of an intrabulbar connection from the inframitral layers to the sensory input layer. These GL-dSACs receive very prominent excitation from $\mathrm{M} / \mathrm{T}$ cells and feed their activity back to the GL through the selective innervation of GABAergic PGCs. The classical interpretation of such a connection is that GL-dSACs disinhibit M/T cells. $\mathrm{GABA}_{\mathrm{A}} \mathrm{R}$-mediated synaptic currents (Puopolo and Belluzzi, 1998; Smith and Jahr, 2002) as well as inhibitory synaptic contacts onto PGCs (Pinching and Powell, 1971a,b; Kosaka et al., 1998) have long been demonstrated. The source of GABA was assumed to originate from other PGCs and superficial SACs (sSACs). Although our results cannot exclude the possibility of PGC-PGC and sSAC-PGC connections, they do reveal a new source of GABAergic input to PGCs. Inhibition of PGCs will not only reduce their inhibition of $\mathrm{M} / \mathrm{T}$ cells, but will also reduce the modulation of synaptic transmission at olfactory sensory neuron terminals mediated by presynaptic $\mathrm{GABA}_{\mathrm{B}}$ and $\mathrm{D}_{2}$ receptors (Aroniadou-Anderjaska et al., 2000; Wachowiak et al., 2005). Finally, GL-dSACs could also play a role in interglomerular synchronization through PGCs, but this remains to be demonstrated experimentally.

Synchronized oscillatory activity is thought to be important for information processing for many sensory modalities, including olfaction (Laurent et al., 2001). In the MOB, mitral cell synchrony is essentially driven by IPSPs imposed by GCs, which are themselves synchronized by their excitatory inputs from mitral cells. The observed rapid synchrony emerges from this precise back-and-forth interplay between neuronal populations (Schoppa, 2006a,b). Lateral inhibition between principal cells of the olfactory bulb is also mediated by circuits that involve these reciprocal dendrodendritic connections, the function of which may be to reveal specific, discrete patterns of glomerular activation (Urban, 2002). Inputs, such as dSACs, that influence GC activity will therefore have a critical effect on oscillatory synchronizations.

As in all nerve cells, GABAergic GCs also receive $\mathrm{GABA}_{\mathrm{A}} \mathrm{R}$ mediated inhibition (Nusser et al., 1999, 2001b; Pressler and Strowbridge, 2006) and express several $\mathrm{GABA}_{\mathrm{A}} \mathrm{R}$ subunits (Fritschy and Möhler, 1995; Nusser et al., 1999, 2001b; SassoèPognetto et al., 2000). Immunohistochemistry has demonstrated the presence of $\alpha 2, \alpha 5, \beta 3, \gamma 2$, and $\delta$ subunits in GCs. Kinetic analysis and benzodiazepine pharmacology of uIPSCs recorded from GCs are consistent with $\alpha 2 \beta 3 \gamma 2$ subunit-containing $\mathrm{GABA}_{\mathrm{A}} \mathrm{Rs}$ being responsible for their synaptic inhibition. Our data demonstrates that the decay of IPSCs is 2.5-fold slower in GCs than in dSACs, consistent with the expression of different $\mathrm{GABA}_{\mathrm{A}}$ receptor subunits in these cell types $(\alpha 1, \beta 2$, and $\gamma 2$ in dSAC vs $\alpha 2, \alpha 5, \beta 3, \gamma 2$, and $\delta$ in GCs) (Fritschy and Möhler, 1995; Nusser et al., 1999). Our physiological characterization of unitary connections between dSACs and GCs revealed variable short-term plasticity, and demonstrated that the plasticity depends on the initial $P_{\mathrm{r}}$. 


\section{References}

Acsády L, Görcs TJ, Freund TF (1996) Different populations of vasoactive intestinal polypeptide-immunoreactive interneurons are specialized to control pyramidal cells or interneurons in the hippocampus. Neuroscience 73:317-334.

Alonso A, Köhler C (1982) Evidence for separate projections of hippocampal pyramidal and non-pyramidal neurons to different parts of the septum in the rat brain. Neurosci Lett 31:209-214.

Alonso JR, Porteros A, Crespo C, Arévalo R, Briñón JG, Weruaga E, Aijón J (1998) Chemical anatomy of the macaque monkey olfactory bulb: NADPH-diaphorase/nitric oxide synthase activity. J Comp Neurol 402:419-434.

Alonso JR, Briñón JG, Crespo C, Bravo IG, Arévalo R, Aijón J (2001) Chemical organization of the macaque monkey olfactory bulb: II. Calretinin, calbindin D-28k, parvalbumin, and neurocalcin immunoreactivity. J Comp Neurol 432:389-407.

Antal M, Eyre M, Finklea B, Nusser Z (2006) External tufted cells in the main olfactory bulb form two distinct subpopulations. Eur J Neurosci 24:1124-1136.

Aroniadou-Anderjaska V, Zhou FM, Priest CA, Ennis M, Shipley MT (2000) Tonic and synaptically evoked presynaptic inhibition of sensory input to the rat olfactory bulb via $\operatorname{GABA}(\mathrm{B})$ heteroreceptors. J Neurophysiol 84:1194-1203.

Aungst JL, Heyward PM, Puche AC, Karnup SV, Hayar A, Szabo G, Shipley MT (2003) Centre-surround inhibition among olfactory bulb glomeruli. Nature 426:623-629.

Blanes T (1898) Sobre algunos puntor dudosos de la estructura del bulbo olfactorio. Rev Trimestral Microgafica 3:99-127.

Briñón JG, Alonso JR, Arévalo R, García-Ojeda E, Lara J, Aijón J (1992) Calbindin D-28k-positive neurons in the rat olfactory bulb. An immunohistochemical study. Cell Tissue Res 269:289-297.

Briñón JG, Martínez-Guijarro FJ, Bravo IG, Arévalo R, Crespo C, Okazaki K, Hidaka H, Aijón J, Alonso JR (1999) Coexpression of neurocalcin with other calcium-binding proteins in the rat main olfactory bulb. J Comp Neurol 407:404-414.

Briñón JG, Weruaga E, Crespo C, Porteros A, Arévalo R, Aijón J, Alonso JR (2001) Calretinin-, neurocalcin-, and parvalbumin-immunoreactive elements in the olfactory bulb of the hedgehog (Erinaceus europaeus). J Comp Neurol 429:554-570.

Carlson GC, Shipley MT, Keller A (2000) Long-lasting depolarizations in mitral cells of the rat olfactory bulb. J Neurosci 20:2011-2021.

Chen WR, Xiong W, Shepherd GM (2000) Analysis of relations between NMDA receptors and GABA release at olfactory bulb reciprocal synapses. Neuron 25:625-633.

Crespo C, Blasco-Ibáñez JM, Briñón JG, Alonso JR, Domínguez MI, Martínez-Guijarro FJ (2000) Subcellular localization of m2 muscarinic receptors in GABAergic interneurons of the olfactory bulb. Eur J Neurosci 12:3963-3974.

Crespo C, Blasco-Ibáñez JM, Marqués-Marí AI, Martínez-Guijarro FJ (2001) Parvalbumin-containing interneurons do not innervate granule cells in the olfactory bulb. Neuroreport 12:2553-2556.

Crespo C, Blasco-Ibáñez JM, Marqués-Marí AI, Alonso JR, Briñón JG, Martínez-Guijarro FJ (2002) Vasoactive intestinal polypeptidecontaining elements in the olfactory bulb of the hedgehog (Erinaceus europaeus). J Chem Neuroanat 24:49-63.

Freund TF, Buzsáki G (1996) Interneurons of the hippocampus. Hippocampus 6:347-470.

Fritschy JM, Möhler H (1995) GABA $_{\mathrm{A}}$-receptor heterogeneity in the adult rat brain: differential regional and cellular distribution of seven major subunits. J Comp Neurol 359:154-194.

Gonchar YA, Johnson PB, Weinberg RJ (1995) GABA-immunopositive neurons in rat neocortex with contralateral projections to S-I. Brain Res 697:27-34.

Gracia-Llanes FJ, Crespo C, Blasco-Ibáñez JM, Marqués-Marí AI, MartínezGuijarro FJ (2003) VIP-containing deep short-axon cells of the olfactory bulb innervate interneurons different from granule cells. Eur J Neurosci 18:1751-1763.

Gulyás AI, Hájos N, Freund TF (1996) Interneurons containing calretinin are specialized to control other interneurons in the rat hippocampus. J Neurosci 16:3397-3411.

Gulyás AI, Hajos N, Katona I, Freund TF (2003) Interneurons are the local targets of hippocampal inhibitory cells which project to the medial septum. Eur J Neurosci 17:1861-1872.

Hayar A, Karnup S, Shipley MT, Ennis M (2004) Olfactory bulb glomeruli: external tufted cells intrinsically burst at theta frequency and are entrained by patterned olfactory input. J Neurosci 24:1190-1199.

Hirata Y (1964) Some observations on the fine structure of the synapses in the olfactory bulb of the mouse, with particular reference to the atypical synaptic configurations. Arch Histol Jpn 24:293-302.

Jahr CE, Nicoll RA (1980) Dendrodendritic inhibition: demonstration with intracellular recording. Science 207:1473-1475.

Jinno S, Klausberger T, Marton LF, Dalezios Y, Roberts JD, Fuentealba P, Bushong EA, Henze D, Buzsáki G, Somogyi P (2007) Neuronal diversity in GABAergic long-range projections from the hippocampus. J Neurosci 27:8790-8804

Kosaka K, Toida K, Aika Y, Kosaka T (1998) How simple is the organization of the olfactory glomerulus?: the heterogeneity of so-called periglomerular cells. Neurosci Res 30:101-110.

Kosaka K, Aika Y, Toida K, Kosaka T (2001) Structure of intraglomerular dendritic tufts of mitral cells and their contacts with olfactory nerve terminals and calbindin-immunoreactive type 2 periglomerular neurons. J Comp Neurol 440:219-235.

Kosaka T, Kosaka K (2007) Heterogeneity of nitric oxide synthasecontaining neurons in the mouse main olfactory bulb. Neurosci Res 57:165-178.

Laurent G (2002) Olfactory network dynamics and the coding of multidimensional signals. Nat Rev Neurosci 3:884-895.

Laurent G, Stopfer M, Friedrich RW, Rabinovich MI, Volkovskii A, Abarbanel HD (2001) Odor encoding as an active, dynamical process: experiments, computation, and theory. Annu Rev Neurosci 24:263-297.

Markram H, Toledo-Rodriguez M, Wang Y, Gupta A, Silberberg G, Wu C (2004) Interneurons of the neocortical inhibitory system. Nat Rev Neurosci 5:793-807.

McBain CJ, Fisahn A (2001) Interneurons unbound. Nat Rev Neurosci 2:11-23.

Meskenaite V (1997) Calretinin-immunoreactive local circuit neurons in area 17 of the cynomolgus monkey, Macaca fascicularis. J Comp Neurol 379:113-132.

Mugnaini E, Oertel WH, Wouterlood FF (1984) Immunocytochemical localization of GABA neurons and dopamine neurons in the rat main and accessory olfactory bulbs. Neurosci Lett 47:221-226.

Murphy GJ, Darcy DP, Isaacson JS (2005) Intraglomerular inhibition: signaling mechanisms of an olfactory microcircuit. Nat Neurosci 8:354-364.

Nickell WT, Shipley MT (1988) Two anatomically specific classes of candidate cholinoceptive neurons in the rat olfactory bulb. J Neurosci 8:4482-4491.

Nusser Z, Sieghart W, Mody I (1999) Differential regulation of synaptic $\mathrm{GABA}_{\mathrm{A}}$ receptors by cAMP-dependent protein kinase in mouse cerebellar and olfactory bulb neurones. J Physiol 521:421-435.

Nusser Z, Naylor D, Mody I (2001a) Synapse-specific contribution of the variation of transmitter concentration to the decay of inhibitory postsynaptic currents. Biophys J 80:1251-1261.

Nusser Z, Kay LM, Laurent G, Homanics GE, Mody I (2001b) Disruption of $\mathrm{GABA}_{\mathrm{A}}$ receptors on GABAergic interneurons leads to increased oscillatory power in the olfactory bulb network. J Neurophysiol 86:2823-2833.

Paxinos G, Watson C (1998) The rat brain in stereotaxic coordinates, Ed 4. San Diego: Academic.

Pinching AJ, Powell TP (1971a) The neuropil of the periglomerular region of the olfactory bulb. J Cell Sci 9:379-409.

Pinching AJ, Powell TP (1971b) The neuropil of the glomeruli of the olfactory bulb. J Cell Sci 9:347-377.

Pressler RT, Strowbridge BW (2006) Blanes cells mediate persistent feedforward inhibition onto granule cells in the olfactory bulb. Neuron 49:889-904.

Price JL, Powell TP (1970a) The mitral and short axon cells of the olfactory bulb. J Cell Sci 7:631-651.

Price JL, Powell TP (1970b) The synaptology of the granule cells of the olfactory bulb. J Cell Sci 7:125-155.

Puopolo M, Belluzzi O (1998) Inhibitory synapses among interneurons in the glomerular layer of rat and frog olfactory bulbs. J Neurophysiol 80:344-349.

Ramón y Cajal S (1911) Histologie du systeme nerveux de l'homme et des vertebres. Paris: Maloine. 
Sassoè-Pognetto M, Panzanelli P, Sieghart W, Fritschy JM (2000) Colocalization of multiple $\mathrm{GABA}_{\mathrm{A}}$ receptor subtypes with gephyrin at postsynaptic sites. J Comp Neurol 420:481-498.

Schneider SP, Macrides F (1978) Laminar distributions of interneurons in the main olfactory bulb of the adult hamster. Brain Res Bull 3:73-82.

Schoppa NE (2006a) Synchronization of olfactory bulb mitral cells by precisely timed inhibitory inputs. Neuron 49:271-283.

Schoppa NE (2006b) AMPA/kainate receptors drive rapid output and precise synchrony in olfactory bulb granule cells. J Neurosci 26:12996-13006.

Shepherd GM, Chen WR, Greer CA (2004) Olfactory bulb. New York: Oxford UP.

Smith TC, Jahr CE (2002) Self-inhibition of olfactory bulb neurons. Nat Neurosci 5:760-766.

Somogyi P, Hodgson AJ (1985) Antisera to g-aminobutyric acid. III. Demonstration of GABA in Golgi-impregnated neurons and in conventional electron microscopic sections of cat striate cortex. J Histochem Cytochem 33:249-257.
Somogyi P, Tamás G, Lujan R, Buhl EH (1998) Salient features of synaptic organisation in the cerebral cortex. Brain Res Rev 26:113-135.

Tibshirani R, Walther G, Hastie T (2001) Estimating the number of clusters in a data set via the gap statistic. J R Statist Soc B 63:411-423.

Tóth K, Freund TF (1992) Calbindin D28k-containing nonpyramidal cells in the rat hippocampus: their immunoreactivity for GABA and projection to the medial septum. Neuroscience 49:793-805.

Urban NN (2002) Lateral inhibition in the olfactory bulb and in olfaction. Physiol Behav 77:607-612.

Wachowiak M, McGann JP, Heyward PM, Shao Z, Puche AC, Shipley MT (2005) Inhibition [corrected] of olfactory receptor neuron input to olfactory bulb glomeruli mediated by suppression of presynaptic calcium influx. J Neurophysiol 94:2700-2712.

Willhite DC, Nguyen KT, Masurkar AV, Greer CA, Shepherd GM, Chen WR (2006) Viral tracing identifies distributed columnar organization in the olfactory bulb. Proc Natl Acad Sci U S A 103:12592-12597.

Xu F, Greer CA, Shepherd GM (2000) Odor maps in the olfactory bulb. J Comp Neurol 422:489-495. 